\title{
Hypoxia-responsive ionizable liposome delivery siRNA for glioma therapy
}

\author{
This article was published in the following Dove Press journal: \\ International Journal of Nanomedicine \\ 8 February 2017 \\ Number of times this article has been viewed
}

\author{
Hong-Mei Liu',2,* \\ Ya-Fei Zhang ${ }^{1,2, *}$ \\ Yan-Dong Xie ${ }^{1,2}$ \\ Yi-Fan Cai ${ }^{1,2}$ \\ Bai-Yang $\mathrm{Li}^{1,2}$ \\ Wen $\mathrm{Li}^{3}$ \\ Ling-Yu Zeng ${ }^{4}$ \\ Yu-Ling $\mathrm{Li}^{4}$ \\ Ru-Tong Yu ${ }^{1,2}$
}

'Department of Neurosurgery, Brain Hospital, Affiliated Hospital of Xuzhou Medical University, ${ }^{2}$ Department of Neurosurgery, Institute of Nervous System Diseases, Xuzhou Medical University, ${ }^{3}$ Department of Hematology, Affiliated Hospital of Xuzhou Medical University,

${ }^{4}$ Department of Chemistry, School of Chemistry and Chemical Engineering, Jiangsu Normal University, Xuzhou, Jiangsu, People's Republic of China

*These authors contributed equally to this work

\begin{abstract}
Here, we report the hypoxia-responsive ionizable liposomes to deliver small interference RNA (siRNA) anticancer drugs, which can selectively enhance cellular uptake of the siRNA under hypoxic and low-pH conditions to cure glioma. For this purpose, malate dehydrogenase lipid molecules were synthesized, which contain nitroimidazole groups that impart hypoxia sensitivity and specificity as hydrophobic tails, and tertiary amines as hydrophilic head groups. These malate dehydrogenase molecules, together with DSPE-PEG2000 and cholesterol, were self-assembled into $\mathrm{O}^{\prime 1}, \mathrm{O}^{1}$-(3-(dimethylamino)propane-1,2-diyl) 16-bis(2-(2methyl-5-nitro-1H-imidazol-1-yl)ethyl) di(hexadecanedioate) liposomes (MLP) to encapsulate siRNA through electrostatic interaction. Our study showed that the MLP could deliver polo-like kinase 1 siRNA (siPLK1) into glioma cells and effectively enhance the cellular uptake of MLP/ siPLK1 because of increased positive charges induced by hypoxia and low $\mathrm{pH}$. Moreover, MLP/ siPLK1 was shown to be very effective in inhibiting the growth of glioma cells both in vitro and in vivo. Therefore, the MLP is a promising siRNA delivery system for tumor therapy.

Keywords: hypoxia responsive, cellular uptake, siRNA delivery, ionizable liposome, hypoxic
\end{abstract} conditions

\section{Introduction}

Gene silencing through RNA interference (RNAi) has been demonstrated as a great potential therapeutic agent for cancer treatment. ${ }^{1,2}$ Accumulating evidences have suggested that small interference RNAs (siRNAs), a class of small regulatory RNAs that recognize and degrade the complementary target messenger RNAs (mRNAs) in a sequence-specific manner at a post-transcriptional level, are linked to cancer formation and progression. ${ }^{3}$ Recently, RNAi-based gene silencing approaches have been demonstrated in humans, and hold promise for cancer treatment. ${ }^{4,5}$ Nevertheless, due to poor stability of siRNA in physiological conditions and its inability to cross cellular membranes, the in vivo delivery of siRNA holds a great challenge and remains a crucial issue for its therapeutic success. ${ }^{6}$ Many kinds of nanosized cationic delivery systems have been developed for siRNAs delivery through electrostatic interaction, such as cationic polymers ${ }^{7-9}$ and cationic lipids, ${ }^{10,11}$ among which cationic lipids are the most widely used for systemic delivery of RNAi therapeutics in vivo. However, the toxicity is still an obstacle to the application of cationic lipids in siRNA delivery. The toxicity of cationic lipids is mainly determined by their cationic nature. ${ }^{12,13}$ The positive zeta potential of nanoparticles (NPs) is required for binding siRNAs and their uptake by tumor cells. Therefore, designing a liposome with high siRNA loading capacity, high transfection efficiency, and low cytotoxicity is of great significance for therapeutic gene delivery, which remains highly challenging.
Correspondence: Hong-Mei Liu; Ru-Tong Yu

Institute of Nervous System Diseases, Xuzhou Medical University, No 84, West of Huaihai Road, Xuzhou 221002, Jiangsu, People's Republic of China

Tel +8651685802008

Email liuhongmei816@sina.com; yu.rutong@163.com 
As positive charge has double-edged roles in siRNA delivery, we should adopt corresponding effective measures to reduce the density of positive charge on the surface of liposomes at $\mathrm{pH} 7.4$ during blood circulation, while increasing the density in tumor environment. To achieve this aim, we chose two established tumor microenvironment signals, namely low extracellular $\mathrm{pH}$ and hypoxia of solid tumors, to increase the positive charge on the surface of liposomes. The density of positive charge in tertiary amines is highly $\mathrm{pH}$-dependent. At the blood $\mathrm{pH}$ (7.4), the tertiary amine head group maintains a neutral or low cationic surface charge density, providing a longer half-life in the circulation and reducing nonspecific cytotoxicity. ${ }^{14-18}$ Once at the acidic $\mathrm{pH}(6.8-6.5)$ of tumor, the tertiary amine head groups become protonated, enhancing cellular uptake of NPs. However, many previously reported $\mathrm{pH}$-sensitive nanosystems do not have a sharp response over this $\mathrm{pH}$ range and sometimes take a long time to respond, resulting in only slight increase in the liposome uptake by tumor cells. ${ }^{19-22}$

Many kinds of nanosized cationic liposomes have been developed for siRNAs delivery. ${ }^{23-25}$ Compared with tertiary amine-modified liposomes for siRNAs delivery, cationic liposomes have dramatic effects on transfection and high toxicity in the body. Therefore, it is clear that the development of new approaches is necessary, in order to improve the transfection of tertiary amine-modified liposomes for siRNAs delivery.

Hypoxia is a salient feature of solid tumors and the levels of hypoxia are more severe in most tumors than in normal tissues. ${ }^{26-29}$ In some tumors, the partial pressures of oxygen are near $0 \mathrm{mmHg}$, compared with the normal tissues $(\sim 30 \mathrm{mmHg}) .{ }^{30}$ Previous studies reported that hypoxic regions in the tumors are more acidic. ${ }^{31}$ Thus, the abovementioned $\mathrm{pH}$-responsive liposomes can obtain the surface positive charge density under tumor hypoxic conditions and will improve the uptake efficiency by tumor cells. It has been demonstrated that the nitro group of nitroimidazoles can be converted to an amino group through a series of selective bioreductions under hypoxic conditions. ${ }^{32,33}$ The zeta potentials of NPs containing nitroimidazoles increase significantly under hypoxic condition because of the presence of positively charged amino groups. However, there are no studies available for siRNA delivery systems using $\mathrm{pH}$ and hypoxia-responsive NPs to improve the transfection efficiency of siRNA.

In this study, we developed the lipid molecules that become positively charged when exposed to low $\mathrm{pH}$ and hypoxia in tumor microenvironment, resulting in enhanced therapeutic efficacy of siRNA (Scheme 1). These lipids (malate dehydrogenases [MDHs]) consisted of three functional moieties: the hydrophobic tails conjugated with nitroimidazoles, a linker, and a tertiary amine head group. We designed the MDH lipid molecules for the following purposes: 1) The MDH combined with DSPE-PEG2000 and cholesterol can prepare the $\mathrm{O}^{\prime 1}, \mathrm{O}^{1}$-(3-(dimethylamino) propane-1,2-diyl) 16-bis(2-(2-methyl-5-nitro- $1 H$-imidazol1-yl)ethyl) di(hexadecanedioate) liposomes (MLP) to load siRNA for inhibition of glioma growth. 2) Tertiary amines as hydrophilic head groups of the MDH are highly $\mathrm{pH}$ dependent: at low $\mathrm{pH}$, with high cationic charge, they can embed siRNA and enhance tumor cellular uptake of MLP, whereas at $\mathrm{pH} 7.4$, they can reduce the density of positive charge on the surface of the MLP to provide a long half-life in the circulation. 3) Nitroimidazoles are converted to aminoimidazole (containing positively charged amino groups) under hypoxic conditions in tumor. Based on this unique feature of the nitroimidazole group, we hypothesized that liposomes would obtain more positive surface charge and enhance the uptake of liposomes under hypoxic conditions. These features made MLP an excellent carrier for delivery of siRNA for tumor therapy.

In the present work, we used MLP to deliver polo-like kinase 1 (PLK1) siRNAs (siPLK1) to cure glioma. PLK1, a serine/threonine-protein, is significantly highly expressed in glioma tissues than in the corresponding normal brain tissues. Cohen et al have proved that the inhibition of PLK1 by siPLK1 caused glioma cell-cycle arrest and increased apoptosis in glioma tumor. ${ }^{34}$ Thus, it was used as a model siRNA drug in our work.

\section{Materials and methods Materials}

Hexadecanedioic acid (HA), 2-(2-methyl-5-nitro1H-imidazol-1-yl) ethanol, 1-ethyl-(3,3-dimethylaminopropyl carbodiimide) (EDC), and dimethylaminopyridine (DMAP) were purchased from TCI Shanghai. Annexin $\mathrm{V}$-fluorescein isothiocyanate (FITC)/propidium iodide (PI) was obtained from Nanjing KeyGEN BioTECH Co. Ltd (Nanjing, People's Republic of China). Hypoxyprobe ${ }^{\mathrm{TM}}-1$ Plus Kit was purchased from Hypoxyprobe, Inc. (Burlington, MA, USA). LysoTracker ${ }^{\mathrm{TM}}$ red was brought from Invitrogen (Carlsbad, CA, USA). DSPE-PEG-2000 and cholesterol were obtained from Shanghai Advanced Vehicle Technology Pharmaceutical Co. Ltd (AVT). 3-(4, 5-Dimethylthiazol-2-yl)-2, 5-diphenyltetrazolium bromide (MTT) was purchased from Beijing Zhongshuo Pharmaceutical Technology Development Co., Ltd. D-Luciferin 
A
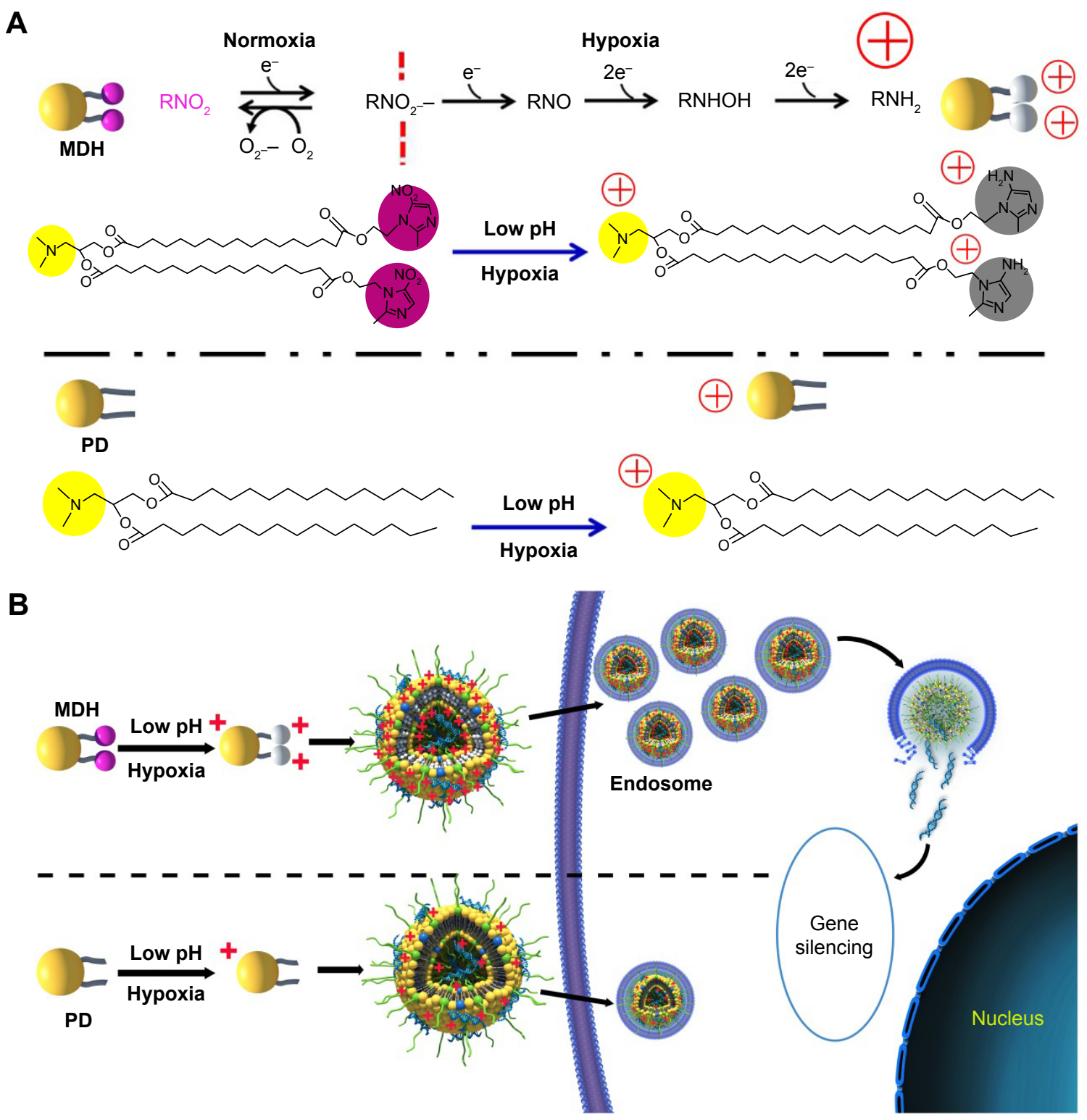

Scheme I Schematic illustration and proposed mechanism.

Notes: (A) Schematic illustration of the mechanism of hypoxia and low-pH-induced increasing positive charges of malate dehydrogenase and (B) proposed mechanism of internalization in hypoxic and low-pH tumor microenvironment.

Abbreviations: PD, Bis(palmitoyloxy)-3-(dimethylamino)propane; $\mathrm{MDH}$, malate dehydrogenase.

potassium salt was got from Dalian Meilun Biotech Co., Ltd (Dalian, People's Republic of China). Transcriptor First Strand cDNA Synthesis Kit and Fast Start Universal SYBR Green Master (Rox) were purchased from Roche (Basel, Switzerland). Enhanced BCA Protein Assay Kit was obtained from Beyotime Biotechnology (Shanghai, People's Republic of China). PLK1 (208G4) Rabbit monoclonal antibody (mAb) was got from Cell Signaling Technology Co., Ltd (Danvers, MA, USA). Beta-actin mAb was bought from Proteintech Antibodies People Trust (Chicago, IL, USA). FAM-labeled siRNA (FAM-siRNA), negative control siRNA with a scrambled sequence (nonsense, antisense strand, 5'-ACGUGACACGUUCGGAGAAdTdT-3'), and siRNA targeting PLK1 mRNA (siPLK1, antisense strand, 5'-AGAUCACUCUCCUCAACUAUU-3') were synthesized by GenePharma Co. Ltd. (Shanghai, People's Republic of China). Cy5-siRNA was brought from Suzhou Biosyntech Co., Ltd (Suzhou, People's Republic of China).

\section{Synthesis of MDH and Bis(palmitoyloxy)- 3-(dimethylamino)propane (PD)}

To a stirred solution of 2-(2-methyl-5-nitro- $1 H$-imidazol-1-yl) ethanol (560 mg, $3.15 \mathrm{mmol}$ ), HA (1 g, $3.5 \mathrm{mmol}$ ), and EDC (668 mg, $3.5 \mathrm{mmol}$ ) in freshly distilled dry dimethylformamide 
(DMF) $(50 \mathrm{~mL})$ was added DMAP $(854 \mathrm{mg}, 7.0 \mathrm{mmol})$ at room temperature and the mixture stirred for $12 \mathrm{~h}$. The solvent was removed under vacuum. The solid thus obtained was purified through flash chromatograph with $\mathrm{MeCN}: \mathrm{H}_{2} \mathrm{O}$ (80\%-100\%). Evaporation of the solvent gave the product as a white solid (16-(2-(2-methyl-5-nitro-1H-imidazol-1-yl) ethoxy)-16-oxohexadecanoic acid, MHA). The yield was $842 \mathrm{mg}(\sim 60 \%):{ }^{1} \mathrm{H}$ nuclear magnetic resonance (NMR) (400 MHz, DMSO-d $) 1.24\left(\mathrm{CH}_{2}, \mathrm{br}, 24 \mathrm{H}\right), 1.33-1.49$ $\left(\mathrm{CH}_{2}-\mathrm{CH}_{2}-\mathrm{C}=\mathrm{O}, \mathrm{m}, 4 \mathrm{H}\right), 2.15-2.22\left(\mathrm{CH}_{2}-\mathrm{C}=\mathrm{O}, \mathrm{m}, 4 \mathrm{H}\right), 2.45$ $\left(\mathrm{CH}_{3}-\mathrm{Im}, \mathrm{s}, 3 \mathrm{H}\right), 4.36\left(\mathrm{CH}_{2}-\mathrm{Im}, \mathrm{t}, J=4.2 \mathrm{~Hz}, 2 \mathrm{H}\right), 4.58\left(\mathrm{CH}_{2}-\right.$ $\mathrm{CH}_{2}-\mathrm{Im}, \mathrm{t}, J=4.2 \mathrm{~Hz}, 2 \mathrm{H}$ ), 8.02 (Im-H, s, 1H), 11.94 (HO$\mathrm{C}=\mathrm{O}$, br, $1 \mathrm{H})$; $\mathrm{MS}(\mathrm{m} / \mathrm{z})$ : $[\mathrm{M}-\mathrm{H}]^{-}$calculated for $\mathrm{C}_{23} \mathrm{H}_{36} \mathrm{~N}_{3} \mathrm{O}_{6}$ 438.26, found 438.29. To a stirred solution of 3-dimethylaminopropane-1, 2-diol (DA) (109 mg, $0.9 \mathrm{mmol}$ ), MHA (842 mg, $1.9 \mathrm{mmol})$, and EDC (366 mg, $1.92 \mathrm{mmol}$ ) in freshly distilled dry DMF (50 mL) was added DMAP (100 mg, $1.9 \mathrm{mmol}$ ) at room temperature and the mixture stirred for $12 \mathrm{~h}$. The solvent was removed under vacuum. The solid thus obtained was purified by passing through a silica gel column using petroleum ether:ethyl acetate (PE:EA) (5:1) as eluent. Evaporation of the solvent gave product as a colorless syrup (MDH). The yield was $770 \mathrm{mg}(\sim 89 \%):{ }^{1} \mathrm{H}$ NMR (400 MHz, $\left.\mathrm{CDCl}_{3}\right) 1.24\left(\mathrm{CH}_{2}\right.$, br, $\left.40 \mathrm{H}\right), 1.54-1.61\left(\mathrm{CH}_{2} \mathrm{C}(=\mathrm{O})-\mathrm{O}, \mathrm{m}\right.$, $8 \mathrm{H}), 2.22-2.32\left(\mathrm{CH}_{2} \mathrm{C}(=\mathrm{O})-\mathrm{O}\right.$ and $\left.\left(\mathrm{CH}_{3}\right)_{2}-\mathrm{N}, \mathrm{m}, 14 \mathrm{H}\right), 2.40$ $\left(\mathrm{CH}_{2} \mathrm{~N}\left(\mathrm{CH}_{3}\right)_{2}, \mathrm{dd}, J=6.4 \mathrm{~Hz}, 8.8 \mathrm{~Hz}, 1 \mathrm{H}\right), 2.51\left(\mathrm{CH}_{3}-\mathrm{Im}, \mathrm{s}\right.$, 6H), 4.08 (O=C-O-CH$-\mathrm{CH}$, dd, $J=6.4 \mathrm{~Hz}, 12.0 \mathrm{~Hz}, 1 \mathrm{H})$, $4.35\left(\mathrm{O}=\mathrm{C}-\mathrm{O}-\mathrm{CH}_{2}-\mathrm{CH}, \mathrm{dd}, J=6.8 \mathrm{~Hz}, 12.0 \mathrm{~Hz}, 1 \mathrm{H}\right), 4.41$ $\left(\mathrm{Im}-\mathrm{CH}_{2}, \mathrm{t}, J=4.2 \mathrm{~Hz}, 4 \mathrm{H}\right), 4.59\left(\mathrm{CH}_{2}-\mathrm{CH}_{2}-\mathrm{Im}, \mathrm{t}, J=4.2 \mathrm{~Hz}\right.$, 4H), 5.16-5.21 ( $\left.\mathrm{CH}_{2}-\mathrm{CH}-\mathrm{CH}_{2}, \mathrm{~m}, 1 \mathrm{H}\right), 7.96$ (H-Im, s, 2H). MS $(m / z): 963.20[\mathrm{M}+\mathrm{H}]^{+}$calculated for $\mathrm{C}_{49} \mathrm{H}_{83} \mathrm{~N}_{7} \mathrm{O}_{12}$ 962.25, found 962.20 .

To a stirred solution of DA (240 mg, $2 \mathrm{mmol})$, palmitic acid (1.07 g, $4.2 \mathrm{mmol}$ ), and EDC (802 $\mathrm{mg}, 4.2 \mathrm{mmol})$ in freshly distilled dry dichloromethane (DCM) $(30 \mathrm{~mL})$ was added DMAP (100 mg) at room temperature and the mixture stirred for $24 \mathrm{~h}$. The solvent was removed under vacuum. The solid thus obtained was purified by passing through a silica gel column using DCM-MeOH (95:5) as eluent. Evaporation of the solvent gave the product as a colorless solid. The yield was $950 \mathrm{mg}(\sim 90 \%)$ : ${ }^{1} \mathrm{H}$ NMR (400 MHz, $\left.\mathrm{CDCl}_{3}\right) 0.88\left(\mathrm{CH}_{3} \mathrm{CH}_{2}, \mathrm{t}, J=6.8 \mathrm{~Hz}, 6 \mathrm{H}\right), 1.25-1.28\left(\mathrm{CH}_{2}, \mathrm{~m}\right.$, $48 \mathrm{H}), 1.59-1.62\left(\mathrm{CH}_{2}-\mathrm{CH}_{2}-\mathrm{C}=\mathrm{O}, \mathrm{m}, 4 \mathrm{H}\right), 2.26-2.32\left(\mathrm{CH}_{3}-\mathrm{N}\right.$ and $\left.\mathrm{CH}_{2}-\mathrm{C}=\mathrm{O}, \mathrm{m}, 10 \mathrm{H}\right), 2.40-2.52\left(\mathrm{CH}_{2}-\mathrm{N}, \mathrm{m}, 2 \mathrm{H}\right), 4.08$ $\left(\mathrm{O}=\mathrm{C}-\mathrm{CH}_{2}-\mathrm{CH}-\mathrm{O}\right.$, dd, $\left.\mathrm{J}=12 \mathrm{~Hz}, 6.4 \mathrm{~Hz}, 2 \mathrm{H}\right), 4.35$ (O=C$\mathrm{CH}_{2}-\mathrm{CH}-\mathrm{O}$, dd, J=12 Hz, 3.2 Hz, 1H), 5.16-5.23 (O-CH$\left.\mathrm{CH}_{2}-\mathrm{C}(=\mathrm{O})-\mathrm{O}, \mathrm{m}, 1 \mathrm{H}\right)$.

\section{Preparation of MLP/siRNA complexes}

MLP/siRNA complex was prepared using ethanol injection method as previously described. ${ }^{35}$ DSPEPEG2000:cholesterol:MDH were completely solubilized in ethanol at a molar ratio of 7.5:35:57.5. The DSPE-PEG2000, cholesterol, and $\mathrm{MDH}$ mixture was added to an aqueous buffer (100 mM citrate, $\mathrm{pH} 3$ ) with mixing to final ethanol and lipid concentrations of $35 \%(\mathrm{v} / \mathrm{v})$ and $3 \mathrm{mg} \mathrm{mL}^{-1}$, respectively. The siRNA (solubilized in a $100 \mathrm{mM}$ citrate, $\mathrm{pH} 3$, $35 \%$ ethanol) was added to the empty MLP. The ethanol was then removed, and the external buffer was replaced with phosphate-buffered saline (PBS, $\mathrm{pH} 7.4$ ) by dialysis using a 3,500 molecular weight cutoff membrane.

\section{Characterization of MLP/siRNA complexes}

MLP and MLP/siRNA complexes were freshly prepared. The mean size and zeta potential of MLP and MLP/siRNA complex were measured by Malvern Zetasizer NanoZS. Transmission electron microscopy (TEM, FEI Tecnai G2 T12) was used to detect particle morphology. Before NPs were measured, $10 \mu \mathrm{L}$ fresh NP sample was placed onto corona plasma-treated, carbon-coated copper grids, and NPs in water were air dried and then negatively stained by a $2 \%$ sodium phosphotungstate solution.

\section{Gel retardation assay}

To test the binding ability of MLP and Bis(palmitoyloxy)3-(dimethylamino)propane liposomes (DLP), gel electrophoresis was carried out. Gel electrophoresis was performed using $2 \%(\mathrm{w} / \mathrm{v})$ agarose gel in TAE buffer with $0.5 \mu \mathrm{g} \mathrm{mL}^{-1}$ of EtBr. MLP and DLP complexes with siRNA at nitrogen/ phosphate (N/P) ratios $0.5,1,5,10$, and 15 were prepared for electrophoresis. Samples were run for $10 \mathrm{~min}$ under 110 $\mathrm{V}$, then visualized using UV exposure.

\section{Hypoxia response experiment}

The condition of hypoxia was generated by the direct depletion of oxygen in sealed environment using the glucose (10 mM), glucose oxidase ( 2 units $\mathrm{mL}^{-1}$ ), and catalase (120 units $\left.\mathrm{mL}^{-1}\right)$ dual enzyme system. Nicotinamide adenine dinucleotide phosphate $(100 \mu \mathrm{M})$ was added as electron donor. ${ }^{35}$ After the last enzyme was added, remaining oxygen in the sealed vessel was excluded by nitrogen immediately. Three hours later, absorption spectra of MLP and DLP under hypoxic and normoxic conditions were detected by a spectrometer. 


\section{In vitro study}

\section{Cell cultures}

Cell cultures under normoxic conditions $\left(\mathrm{pO}_{2}: 21 \%\right)$ were maintained in a humidified incubator at $37^{\circ} \mathrm{C}$ in $5 \% \mathrm{CO}_{2}$ and $95 \%$ air. Hypoxic conditions $\left(\mathrm{pO}_{2}: 2 \%\right)$ were produced by placing cells in a hypoxia incubator (Thermo Scientific HERAcell $150 \mathrm{i}$ ) in a mixture of $2 \% \mathrm{O}_{2}, 5 \% \mathrm{CO}_{2}$, and $93 \% \mathrm{~N}_{2}$.

\section{Intracellular uptake}

To assess the intracellular trafficking of MLP/siRNA complex, fluorescence microscope was used. 66 cells at a density of $5 \times 10^{4}$ were seeded in 12-well culture plates and cultured at $37^{\circ} \mathrm{C}$ in a $5 \% \mathrm{CO}_{2}$ humidified atmosphere with Dulbecco's Modified Eagle's Medium (DMEM) containing 10 vol \% fetal bovine serum (FBS) for $24 \mathrm{~h}$. Later, old medium was replaced with fresh medium (free of FBS). Then the cells were treated with different FAM-siRNA NPs at a dose of FAM-siRNA $1 \mu \mathrm{g} \mathrm{mL}^{-1}$ in the context of normoxia or hypoxia for $4 \mathrm{~h}$. Later, the transfection medium was removed and the cells were stained with Hoechst 33342 (1:1,000) for $10 \mathrm{~min}$ and then they were washed three times with PBS. After that they were observed under a fluorescence microscope.

To evaluate the cellular uptake of siRNA NPs, flow cytometric analysis was used. $\mathrm{C} 6$ cells at a density of $5 \times 10^{4}$ were cultured in 12 -well culture plates at $37^{\circ} \mathrm{C}$ in a $5 \% \mathrm{CO}_{2}$ humidified atmosphere with DMEM containing 10 vol \% FBS for $24 \mathrm{~h}$. Later, old medium was replaced with fresh medium (free of FBS). Then the cells were treated with different FAM-siRNA NPs at a dose of $1 \mu \mathrm{g} \mathrm{mL}^{-1}$ in the context of normoxia or hypoxia for $4 \mathrm{~h}$. The cells were trypsinized, washed three times with cold PBS, and resuspended in $500 \mu \mathrm{L}$ cold PBS for flow cytometric analysis using a BD FACSCalibur Flow Cytometer.

\section{Confocal laser scan microscopy}

To assess the intracellular trafficking of MLP/siRNA complex, confocal laser scan microscopy (CLSM) was used. C6 cells at a density of $5 \times 10^{4}$ were seeded in a $35-\mathrm{mm}$ glass bottom culture dish and incubated for $24 \mathrm{~h}$ at $37^{\circ} \mathrm{C}$ in $5 \% \mathrm{CO}_{2}$. Later, old medium was replaced with fresh medium (free of FBS). Then the cells were treated with different FAM-siRNA NPs at a dose of $1 \mu \mathrm{g} \mathrm{mL}^{-1}$ FAM-siRNA in the context of normoxia or hypoxia for 2 and $4 \mathrm{~h}$, respectively. Later, the transfection medium was removed and the cells were stained with Hoechst $33342(1: 1,000)$ for $10 \mathrm{~min}$ and then washed three times with PBS. Then the cells were stained with LysoTracker Red (1:10,000). The CLSM imaging was conducted by FV10i. The LysoTracker Red, FAM-siRNA, and Hoechst 33342 were excited at 577, 480, and $352 \mathrm{~nm}$, respectively.

\section{Quantitative real-time polymerase chain reaction}

The PLK1 mRNA expression levels in C6 cells of different groups were analyzed by quantitative real-time polymerase chain reaction (qRT-PCR). At the beginning, total RNA was extracted using trizol reagent (TIANGEN) according to the manufacturer's instructions, and possible DNA contamination was removed through digesting the extracted RNA with DNase I. Then, the RNA was purified again using TRIzol reagent and subjected to the synthesis of first-strand cDNA using a reverse transcription kit. Finally, the quantitative analysis of the cDNA was calculated by a qRT-PCR machine (750 ABI USA), and GADPH was amplified as an interior control. All primers were synthesized by Sangon Biotech (Shanghai, People's Republic of China).

\section{Western blot study}

The ability of the siRNA delivered by MLP complex to silence the target protein was researched by Western blotting. C6 cells $\left(2 \times 10^{5}\right)$ were seeded in a six-well culture plate and cultured at $37^{\circ} \mathrm{C}$ in $5 \% \mathrm{CO}_{2}$ for $24 \mathrm{~h}$. After that the cells were treated with different siRNA NPs at a dose of $1 \mu \mathrm{g} \mathrm{mL}^{-1}$ siPLK1 for $24 \mathrm{~h}$ (medium was free of FBS). The group of hypoxia were cultured at $37^{\circ} \mathrm{C}$ in a $2 \% \mathrm{O}_{2}$ and $5 \% \mathrm{CO}_{2}$ humidified atmosphere for $24 \mathrm{~h}$ (medium was free of FBS). Thereafter, the PLK1 protein levels in C6 cells of different groups were analyzed by the method of Western blotting: cultured cells (on ice) were washed twice with cold PBS and lysed. Then the lysis buffer was centrifuged at a speed of $12,000 \mathrm{rpm}$ for 10 min to wipe out impurities. Quantities and equilibriums of the extracted protein samples were measured by BCA kit (Beyotime, Shanghai, People's Republic of China). Before loading on gels, the extracted protein samples were heated at $100^{\circ} \mathrm{C}$ for $10 \mathrm{~min}$. The Western blot was performed according to the manufacturer's protocol (Invitrogen). Precast NupageTris-Bis $(10 \%)$ gels were used for running the protein samples. Magic mark $1 \mathrm{~Kb}$ protein ladder was used as a standard. The gel was electrophoretically transferred to a nitrocellulose membrane using SemiDry blot apparatus (Invitrogen). The membrane was then incubated overnight with primary antibodies. After three washes in Tris Buffered Saline Tween (TBST), the membrane was incubated with secondary antibodies for $1.5 \mathrm{~h}$. The membranes were 
then washed three times in TBST followed by detection of signal with a chemiluminescence detection kit. Finally, the membranes were exposed in a dark room.

\section{Apoptosis study}

To evaluate apoptosis analysis, C6 cells at a density of $1 \times 10^{5}$ cells per well were cultured in six-well plates and cultured at $37^{\circ} \mathrm{C}$ in a $5 \% \mathrm{CO}_{2}$ for $24 \mathrm{~h}$. Then the cells were treated with different siRNA NPs at a dose of $1 \mu \mathrm{g} \mathrm{mL}^{-1}$ siPLK1 for $4 \mathrm{~h}$ (medium was free of FBS). The group of hypoxia were cultured at $37^{\circ} \mathrm{C}$ in a $2 \% \mathrm{O}_{2}$ and $5 \% \mathrm{CO}_{2}$ humidified atmosphere for $4 \mathrm{~h}$ (medium was free of FBS). After that all the medium was replaced with fresh one and the cells were continually cultured for $48 \mathrm{~h}$. The cells were then collected, washed three times with cold PBS, and resuspended in $500 \mu \mathrm{L}$ binding buffer. Then $5 \mu \mathrm{L}$ Annexin V-FITC and $5 \mu \mathrm{L}$ PI were added and incubated with the cells for $15 \mathrm{~min}$ in the dark. Finally, the stained cells were analyzed by a flow cytometer.

\section{Proliferation inhibition study}

The cytotoxicity of MLP was detected by the 3-(4, 5-dimethylthiazol-2-yl)-2, 5-diphenyltetrazolium bromide (MTT) assay. $8000 \mathrm{C} 6$ cells were seeded in a 96-well tissue culture plate and cultured at $37^{\circ} \mathrm{C}$ in a $5 \% \mathrm{CO}_{2}$ humidified atmosphere in $200 \mu \mathrm{L}$ DMEM containing 10 vol \% FBS for $24 \mathrm{~h}$. Then different concentrations of MLP solutions were added and incubated for $24 \mathrm{~h}$. After that $20 \mu \mathrm{L}$ MTT reagent ( $5 \mathrm{mg} \mathrm{mL}^{-1}$ ) was added to each well and incubated for an additional $4 \mathrm{~h}$. The medium was removed lightly and $150 \mu \mathrm{L}$ DMSO was added to each well for 15 min to dissolve purple formazan. Finally, quantification measurements (optical density) were obtained at a wavelength of $570 \mathrm{~nm}$ using a spectrophotometric analysis.

\section{In vivo study \\ Mice}

$\mathrm{BALB} / \mathrm{c}$ nude mice (male, 16-20 g) and ICR mice (male, 18-20 g) were purchased from Beijing HFK Bioscience Co., Ltd. (Beijing, People's Republic of China). BALB/c nude mice were used to study the inhibition of glioma growth. ICR mice were used for pharmacokinetics and biodistribution of MLP/Cy5-siRNA assay. All animals received care in compliance with the guidelines in the Guide for the Care and Use of Laboratory Animals. All procedures were approved by Xuzhou Medical University of China Animal Care and Use Committee.

\section{Tumor model}

C6 cells $\left(1 \times 10^{5}\right.$ cells suspended in $4 \mu \mathrm{L}$ L15 medium) were injected over $8 \mathrm{~min}$ into the right striatum (1 $\mathrm{mm}$ posterior and $1.8 \mathrm{~mm}$ lateral to the bregma, $3 \mathrm{~mm}$ depth inferior to the skull and return pin $0.5 \mathrm{~mm}$ ) of male nude mice using a stereotactic fixation device with a mouse adaptor. Before being removed, microsyringe should be kept still for at least 5 min. After 10 days of xenograft glioma, nude mice were randomly divided into five groups $(n=5)$ and housed in a controlled-temperature room with regular alternating cycles of light and darkness.

\section{Pharmacokinetics assay}

To determine pharmacokinetics, free FAM-siRNA (at $1 \mathrm{mg} \mathrm{kg}^{-1}$ ), DLP/FAM-siRNA, and MLP/FAMsiRNA (at FAM-siRNA concentration of $1 \mathrm{mg} \mathrm{kg}^{-1}$ ) were intravenously injected into ICR mice through the tail vein using a syringe. A blood sample $(40 \mu \mathrm{L})$ was collected from the tail vein at different time points postinjection and mixed with K3-EDTA $(0.5 \mu \mathrm{L}$, an anticoagulation agent). Then the solution was centrifuged $(10,000 \mathrm{~g}, 10 \mathrm{~min})$. The fluorescence intensity of the plasma supernatant was measured using a microplate reader (Bio Tek Synergy H4 Hybrid Reader) with excitation at $485 \mathrm{~nm}$ and emission at $520 \mathrm{~nm}$. The dataset was analyzed using PKSlover software. All data were expressed as mean $\pm \operatorname{SD}(n=5)$.

\section{Biodistribution of MLP/Cy5-siRNA and tissue staining}

After 10 days of xenograft glioma, glioma model ICR mice were first injected with freshly prepared luciferin substrate and imaged with the Xenogen IVIS Spectrum optical imaging device to prove to have similar-volume tumors in the brain. After that, glioma model ICR mice were injected intravenously with free Cy5-siRNA, DLP/Cy5-siRNA, and MLP/ Cy5-siRNA through the tail vein at the dose of $1 \mathrm{mg} \mathrm{kg}^{-1}$ Cy5-siRNA per animal. PBS was injected as control. Then at $4 \mathrm{~h}$ after administration, the mice were killed, and the glioma model brains and other principal organs (heart, liver, spleen, lung, and kidney) were excised carefully and visualized under the in vivo real-time fluorescence imaging system.

The excised glioma model brains were then fixed with $4 \%$ paraformaldehyde for $72 \mathrm{~h}$ and further dehydrated in sucrose solution. Slices of $20 \mu \mathrm{m}$ thickness were prepared and stained with 4',6-diamidino-2-phenylindole (DAPI) for $10 \mathrm{~min}$ at room temperature. The slices were observed under fluorescence microscopy and photographed (Olympus, Takachiho, Japan). 


\section{Assay of tissue hypoxia pimonidazole adducts}

For hypoxic tissue staining, pimonidazole hydrochloride $\left(\right.$ Hypoxyprobe $\left.^{\mathrm{TM}}-1\right)$ as a hypoxic staining probe was used. Pimonidazole is reductively activated in hypoxic cells. The activated intermediate forms stable covalent adducts with thiol (sulphydryl) groups in proteins, peptides, and amino acids. The antibody reagent MAb1 binds to these adducts, allowing their detection by immunochemical means. Pimonidazole hydrochloride $\left(60 \mathrm{mg} \mathrm{kg}^{-1}\right)$ was intravenously injection into the tail vein of C6-GFP-luci tumor-bearing mice. Sixty minutes later, brain tissues were removed from the killed mice, and fixed with $4 \%$ paraformaldehyde solution for $<24 \mathrm{~h}$. Then, the brain tissues were cut into slices. The slices were incubated with hypoxyprobe-MAb1 overnight at $4{ }^{\circ} \mathrm{C}$ (working dilutions 1:50) and with fluorescent rabbit antimouse antibody (1:1,000 dilution, Cell Signaling) for $90 \mathrm{~min}$. In all slices, immunofluorescence was evaluated by fluorescence microscopy.

\section{Antitumor experiments}

Glioma cells (C6 cells) were transformed with luciferase gene (C6-green fluorescent protein [GFP]-luci). The realtime fluorescence imaging analysis was used to evaluate the therapeutic efficiency of different types of formulation from 10 to 27 days after tumor implantation. Twenty-five tumor-bearing mice were randomly divided into five groups to receive different types of formation. At days 10, 12, 14, and 16 after implantation, mice received PBS, free siPLK1, MLP/nonsense siRNA, DLP/siPLK1, and MLP/siPLK1 through the tail vein containing siPLK1 $\left(1 \mathrm{mg} \mathrm{kg}^{-1}\right)$ per dose. The mice were injected with $15 \mathrm{mg} \mathrm{kg}^{-1}$ of freshly prepared luciferin substrate suspended in PBS. The mice were anesthetized with isoflurane $\left(1.0 \mathrm{~L} \mathrm{~min}^{-1}\right.$ oxygen in $4 \%$ isoflurane), and imaged using the IVIS kinetic imaging system (Caliper Life Sciences, Hopkinton, MA, USA). The images were acquired at $15 \mathrm{~min}$ after the intraperitoneal injection of luciferin. Tumor growth was monitored by live bioluminescence imaging with the Xenogen IVIS Spectrum optical imaging device (Caliper Life Sciences) at different time points. The bioluminescence signals were analyzed by using the Living Image Software (Caliper Life Sciences). In addition, the body weight was monitored.

\section{Organ safety evaluation}

C6-GFP-luci tumor-bearing mice received injections of PBS, free siPLK1, MLP/nonsense siRNA, DLP/siPLK1, and
MLP/siPLK1 at a dose of $1 \mathrm{mg} \mathrm{kg}^{-1}$ siRNA on days 10,12 , 14, and 16. Twenty-four hours after the last injection, the mice were killed for organ safety search. The main organs, including heart, lung, kidney, and liver, were collected and sections of the organs were stained with hematoxylin and $\operatorname{eosin}(\mathrm{H} \& \mathrm{E})$.

\section{Statistical analysis}

Statistical analysis was performed using Student's $t$-tests with $* P<0.05$ considered as significant. The experimental results were given in the format of mean and mean \pm SD in the figures.

\section{Results and discussion Synthesis and physiochemical properties of MLP}

In this work, we synthesized the lipid molecule MDH. The chemical structure of MDH is shown in Figure 1A. First, 2-methyl-5-nitroimidazole-1-ethanols (MIs, metronidazole) were conjugated with HA with a hydrolysable ester bond, in order to form MHA. MHA was then coupled with DA to form ester-linked MDH. The formation of MDH was confirmed by ${ }^{1} \mathrm{H}$ NMR spectroscopy and showed all the characteristic peaks and integration values of MDH as indicated in Figure 1C. These data indicated that MDH had been synthesized. As a control lipid molecule, we synthesized PD with no MI group at the end of the alkyl chain. The chemical structure of PD is shown in Figure 1B, which was confirmed by ${ }^{1} \mathrm{H}$ NMR spectroscopy with all the characteristic peaks and the integration values of $\mathrm{PD}$, as indicated in Figure $\mathrm{S} 1$.

After its successful synthesis, MDH, DSPE-PEG2000, and cholesterol were allowed to self-assemble into a liposome (MLP) by ethanol injection method. MLP/siRNA complexes were made as previously reported. ${ }^{10,35,37}$ As shown in Figure 2A, we found that MLP had strong ability to bind siRNA, which completely complexed siRNA at an N/P ratio of 5:1 (the molar ratio of nitrogen in MLP to phosphate in siRNA) through electrostatic interaction, leading to no free siRNA in the gel. The control liposome (DLP) was prepared by PD, DSPE-PEG2000, and cholesterol, and was mixed with siRNA in $\mathrm{pH}=3$ citrate buffer at the optimal N/P ratio of 5:1 (Figure S2). The above results indicated that MIs were not affected by the entrapment efficiency of siRNA in low $\mathrm{pH}$ value. Figure $2 \mathrm{~B}$ presents a representative TEM image of MLP/siRNA complexes prepared with an N/P ratio of $5: 1$, revealing the formation of double-layer structure with a uniform diameter of $\sim 100 \mathrm{~nm}$, which is consistent with the 
A

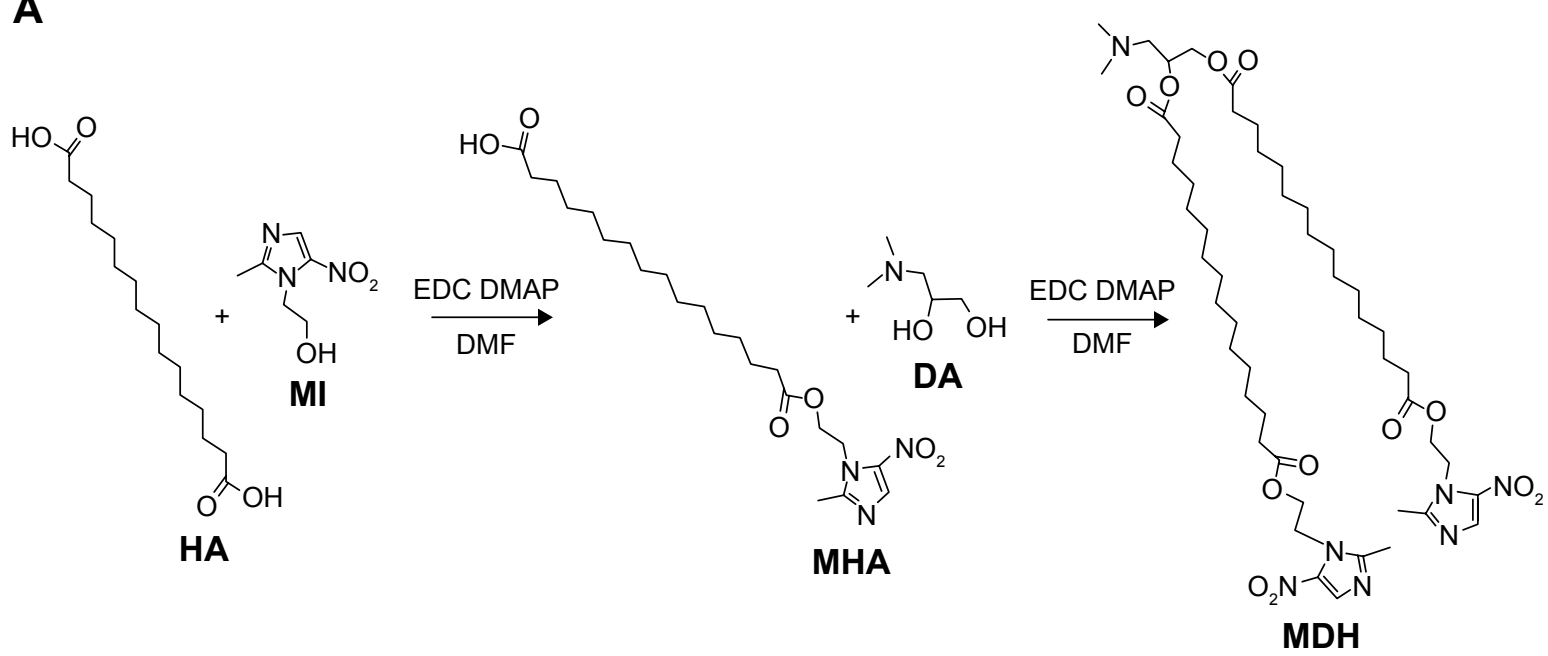

B

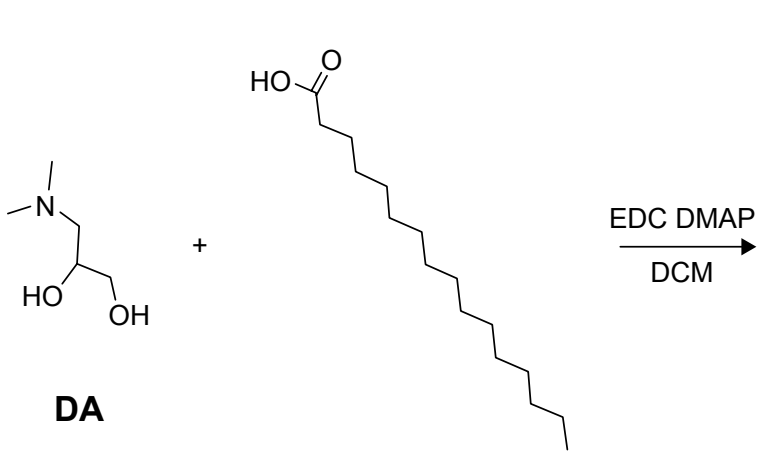

PA

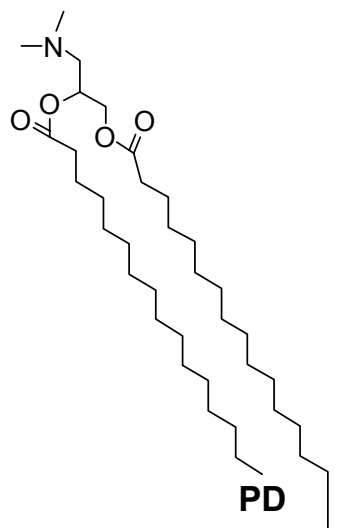

C

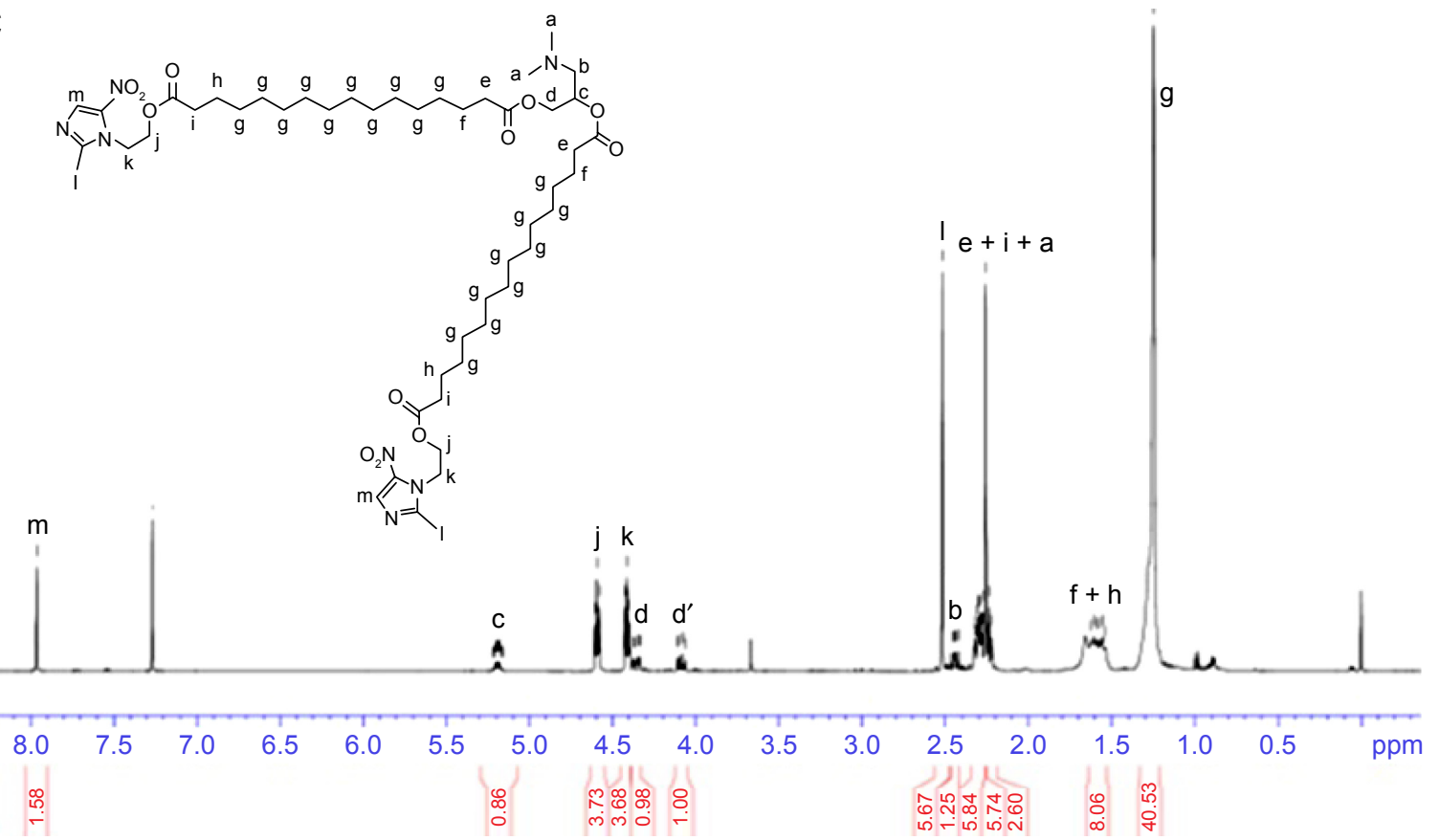

Figure I The synthetic routes of $\mathrm{MDH}$ and PD.

Notes: (A) The synthetic routes for MDH lipid molecules. (B) The synthetic routes for PD lipid molecules. (C) ' $\mathrm{H}$ NMR spectra of $M D H(400$ MHz, $\mathrm{CDCl}$ ).

Abbreviations: DA, 3-dimethylaminopropane-I, 2-diol; HA, hexadecanedioic acid; MDH, malate dehydrogenase; EDC, I-ethyl-(3,3-dimethylaminopropyl carbodiimide);

DMAP, dimethylaminopyridine; MI, 2-methyl-5-nitroimidazole-I-ethanol; MHA, (16-(2-(2-methyl-5-nitro-IH-imidazol-I-yl) ethoxy)-I6-oxohexadecanoic acid; PD, Bis(palmitoyloxy)-3-(dimethylamino)propane; PA, polyamide; DMF, dimethylformamide; NMR, nuclear magnetic resonance. 
A

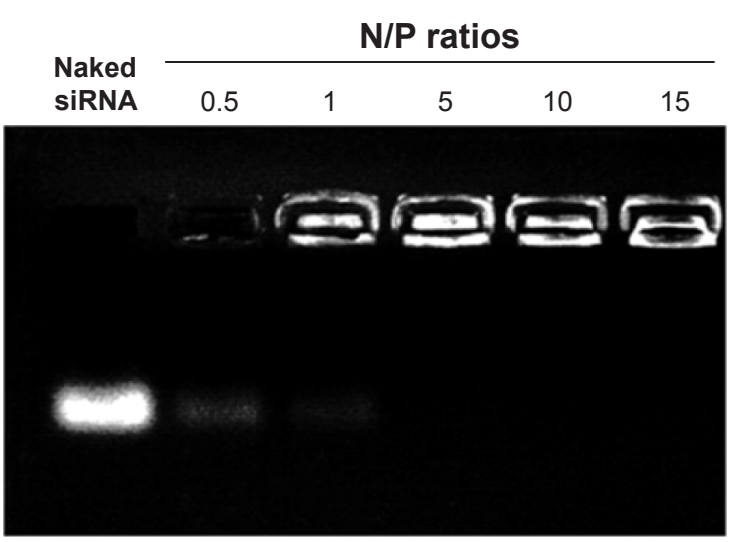

C

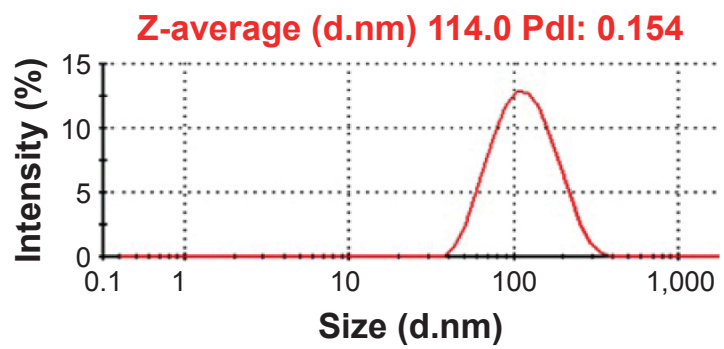

B

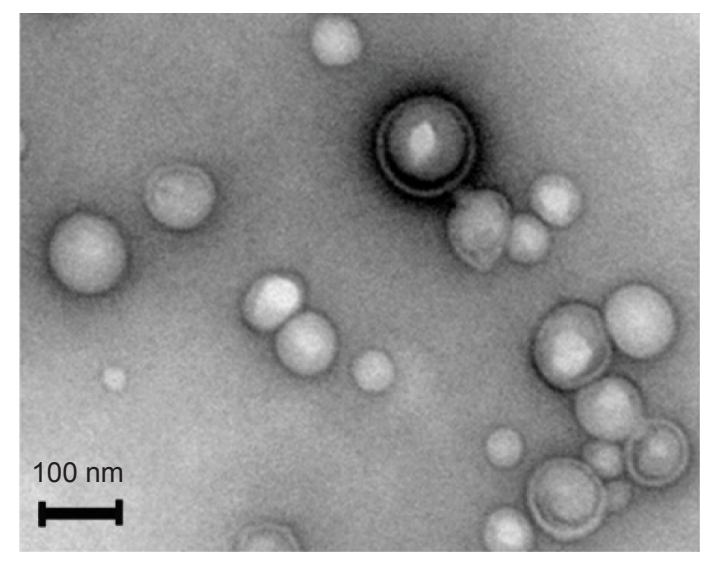

D

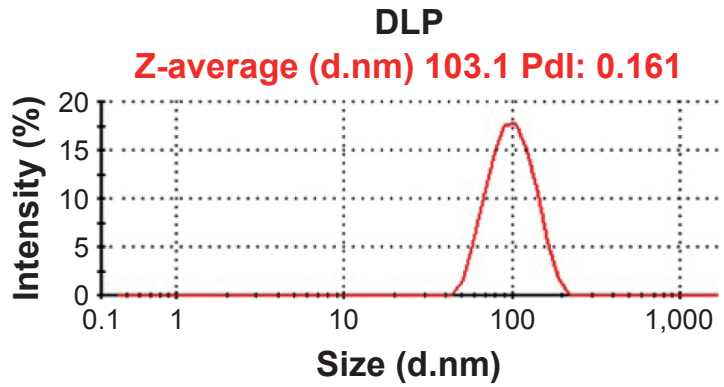

Figure $2 \mathrm{Gel}$ retardation and spectrometer assay for MLP/siRNA complexes.

Notes: (A) Gel retardation assay of complexation efficiency of siRNA at various N/P ratios. (B) Transmission electron microscopic image of MLP/siRNA complexes. (C) The DLS size distribution by intensity of MLP. (D) The DLS size distribution by intensity of DLP.

Abbreviations: DLP, Bis(palmitoyloxy)-3-(dimethylamino)propane liposomes; DLS, dynamic light scatter; MLP, O'I,O'-(3-(dimethylamino)propane-I,2-diyl) I6-bis(2-(2methyl-5-nitro- IH-imidazol-I-yl)ethyl) di(hexadecanedioate) liposomes; siRNA, small interference RNA; N/P nitrogen/phosphate.

measurement obtained using dynamic light scattering around 100-120 nm (Figure 2C). The average diameter of MLP was higher than that of DLP (Figure 2D).

Many studies have reported that tertiary amines possess positive charge density in low $\mathrm{pH}^{14-16}$ and the nitro group of $\mathrm{MI}$ is converted to an amino group under low-oxygen conditions. ${ }^{32,33}$ Because of this, MDH will have the above nature. It would have more positive charge under low-pH and hypoxic conditions. To evaluate the properties of MLP under these conditions, the zeta potential of MLP was measured by DLS. DLP had an average zeta potential of 3.4 and $7.3 \mathrm{mV}$ in PBS ( $\mathrm{pH}=7.4$ and 3 ) and $5.7 \mathrm{mV}$ under hypoxia (Figure $3 \mathrm{~A}$ $[\mathrm{a}-\mathrm{c}])$. MLP had an average zeta potential of 3.9, 10.6, and $16.8 \mathrm{mV}$ under corresponding conditions (Figure $3 \mathrm{~B}[\mathrm{a}-\mathrm{c}]$ ). The zeta potential of MLP and DLP increased in PBS at $\mathrm{pH} 3$, indicating that the tertiary amine head groups of MLP and DLP became protonated and positively charged. These results are consistent with the previously reported values. ${ }^{11,15}$ Furthermore, compared with DLP, the zeta potential of MLP increased significantly under hypoxia, indicating that the nitroimidazole groups of MLP are converted to aminoimidazoles and become positively charged.

To further confirm the conversion of nitroimidazoles to aminoimidazoles, the absorption spectra of MLP and
DLP were measured. As shown in Figure 4, there was a characteristic peak of MLP at $325 \mathrm{~nm}$, corresponding to the characteristic peak of MI, and not the characteristic peak of MI at $325 \mathrm{~nm}$ of DLP under normoxic conditions. Meanwhile, under hypoxic conditions, the characteristic peak of MI at $325 \mathrm{~nm}$ completely disappeared, indicating that the nitro group of MI is converted to an amino group under low-oxygen conditions. Compared with DLP under normoxic conditions, the characteristic absorption peak of DLP remained unchanged under hypoxic conditions. Based on this unique feature of the MI derivative, we hypothesized that the MLP/siRNA would be positively charged and enhanced the uptake by tumor cells under low-pH and hypoxic tumor microenvironment. The cytotoxicity of the MLP was evaluated by the MTT assay against C6 cells. As shown in Figure S3, the cell viability was $>80 \%$ when the concentration of MLP was up to $500 \mu \mathrm{g} \mathrm{mL}^{-1}$, indicating that the cytotoxicity of MLP was fairly low.

\section{Intracellular uptake of MLP/siRNA by C6 cells}

A study has reported that NPs with positive surface charge have enhanced selective cellular uptake. ${ }^{38}$ Earlier, we demonstrated that the zeta potential of MLP increased 
A a

DLP

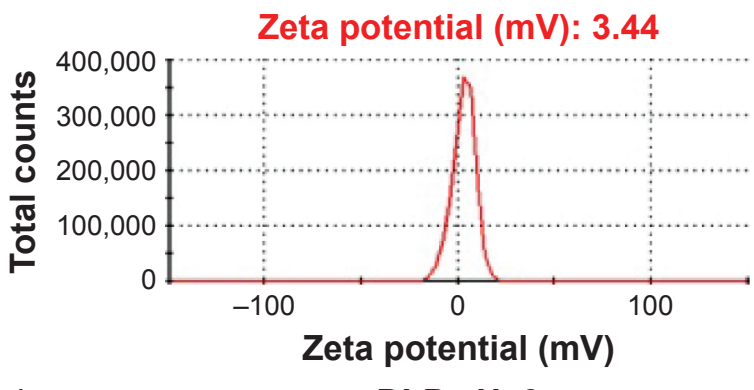

b

DLP $\mathrm{pH}=3$

Zeta potential $(\mathrm{mV}): \mathbf{7 . 3 5}$

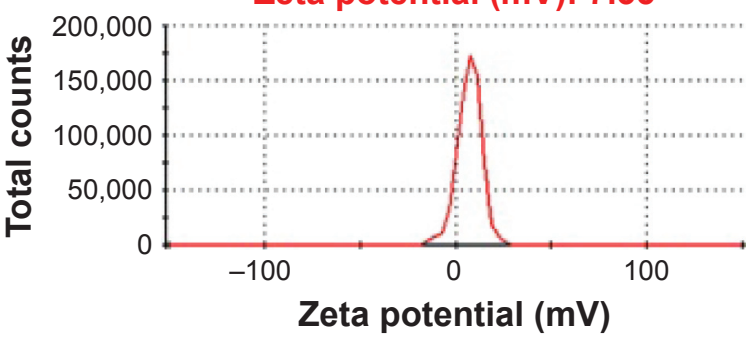

C

DLP hypoxia

Zeta potential $(\mathrm{mV}): \mathbf{5 . 7 4}$

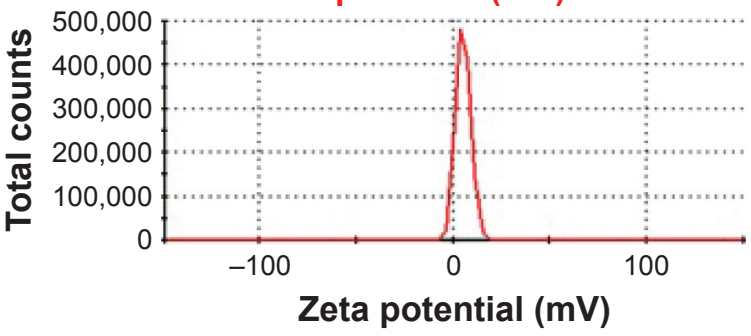

B a

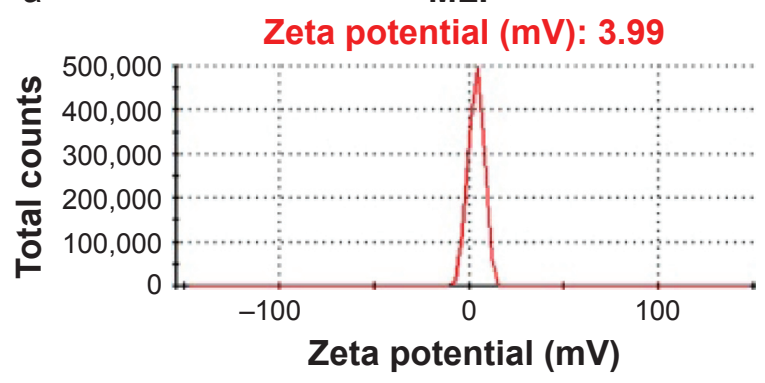

b MLP $\mathrm{pH}=3$

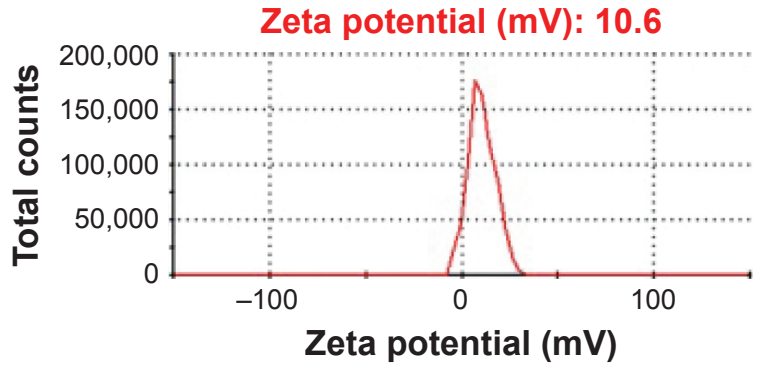

C

MLP hypoxia

Zeta potential $(\mathrm{mV}): 16.8$

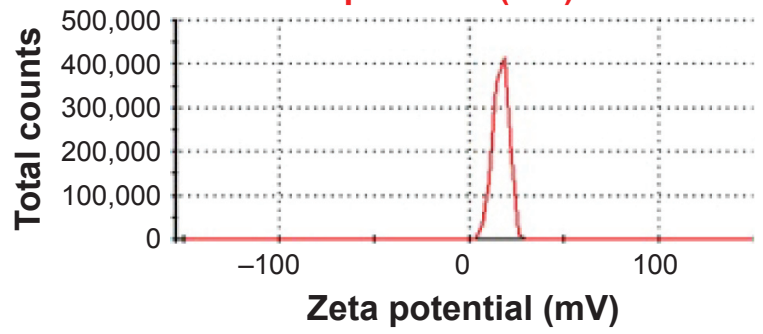

Figure 3 The spectrometer assay for hypoxia response experiment of MLP and DLP.

Notes: (A) The zeta potential of DLP (a) in $\mathrm{pH}=7.4 \mathrm{PBS}$, (b) in $\mathrm{pH}=3 \mathrm{PBS}$, (c) under hypoxia. (B) The zeta potential of $\mathrm{MLP}$ (a) in pH=7.4 PBS, (b) in pH=3 PBS, (c) under hypoxia. Abbreviations: DLP, Bis(palmitoyloxy)-3-(dimethylamino)propane liposomes; MLP, O' ', O'-(3-(dimethylamino)propane-I, 2-diyl) I6-bis(2-(2-methyl-5-nitro-I H-imidazol-I-yl) ethyl) di(hexadecanedioate) liposomes; PBS, phosphate-buffered saline.

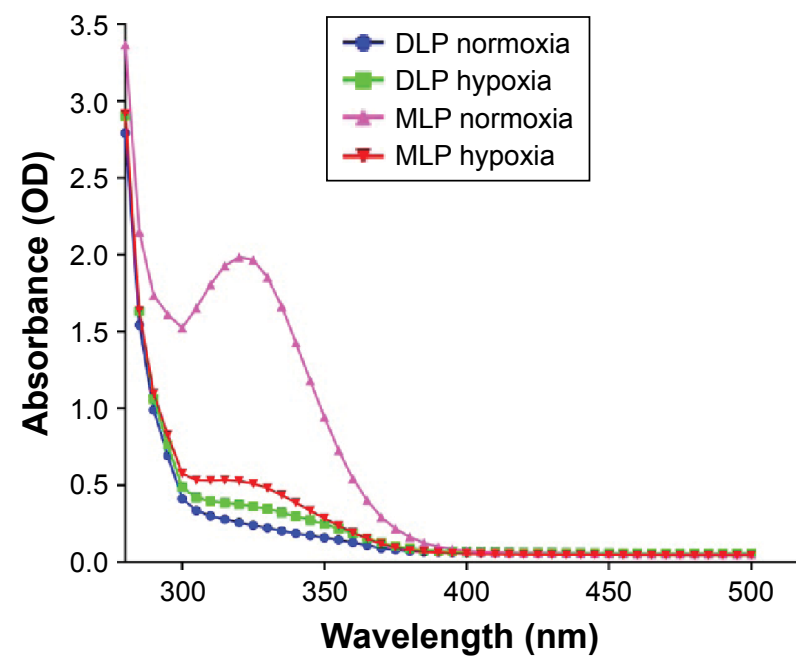

Figure 4 Absorption spectra of MLP and DLP.

Notes: MLP and DLP were incubated under hypoxic and normoxic conditions for $3 \mathrm{~h}$. Measurements were performed in phosphate-buffered saline buffer containing nicotinamide adenine dinucleotide phosphate as an electron donor (the illustration shows the conversion of nitroimidazole into aminoimidazole).

Abbreviations: DLP, Bis(palmitoyloxy)-3-(dimethylamino)propane liposomes; MLP, $\mathrm{O}^{\prime \prime}, \mathrm{O}^{\prime}$-(3-(dimethylamino)propane-I,2-diyl) I6-bis(2-(2-methyl-5-nitro- IHimidazol-I-yl)ethyl) di(hexadecanedioate) liposomes; OD, optical density. significantly under hypoxic and low-pH conditions. Whether MLP could enhance the cellular uptake under hypoxic and low-pH conditions, and the cellular uptake and intracellular distribution of the MLP/siRNA were studied by fluorescence microscopy and flow cytometry. To evaluate the effect of hypoxia on the uptake of the MLP/siRNA by glioma cells, FAM-siRNA was encapsulated into MLP. Cellular uptake was monitored after incubating the cells with MLP/FAMsiRNA for $4 \mathrm{~h}$ under normoxic and hypoxic conditions. As shown in Figure 5A, DLP/FAM-siRNA showed similar intracellular fluorescence intensity in glioma cells under normoxic and hypoxic conditions. However, the MLP-based siRNA lipoplexes (MLP/FAM-siRNA) showed higher cellular internalization than DLP/siRNA, especially under hypoxic conditions. The results were further confirmed by fluorescent microscopy. The strongest green fluorescence was found in the glioma cells incubated with MLP/FAM-siRNA under hypoxic condition (Figure 5B). This is likely because that MLP has more positive surface charges under hypoxia. 

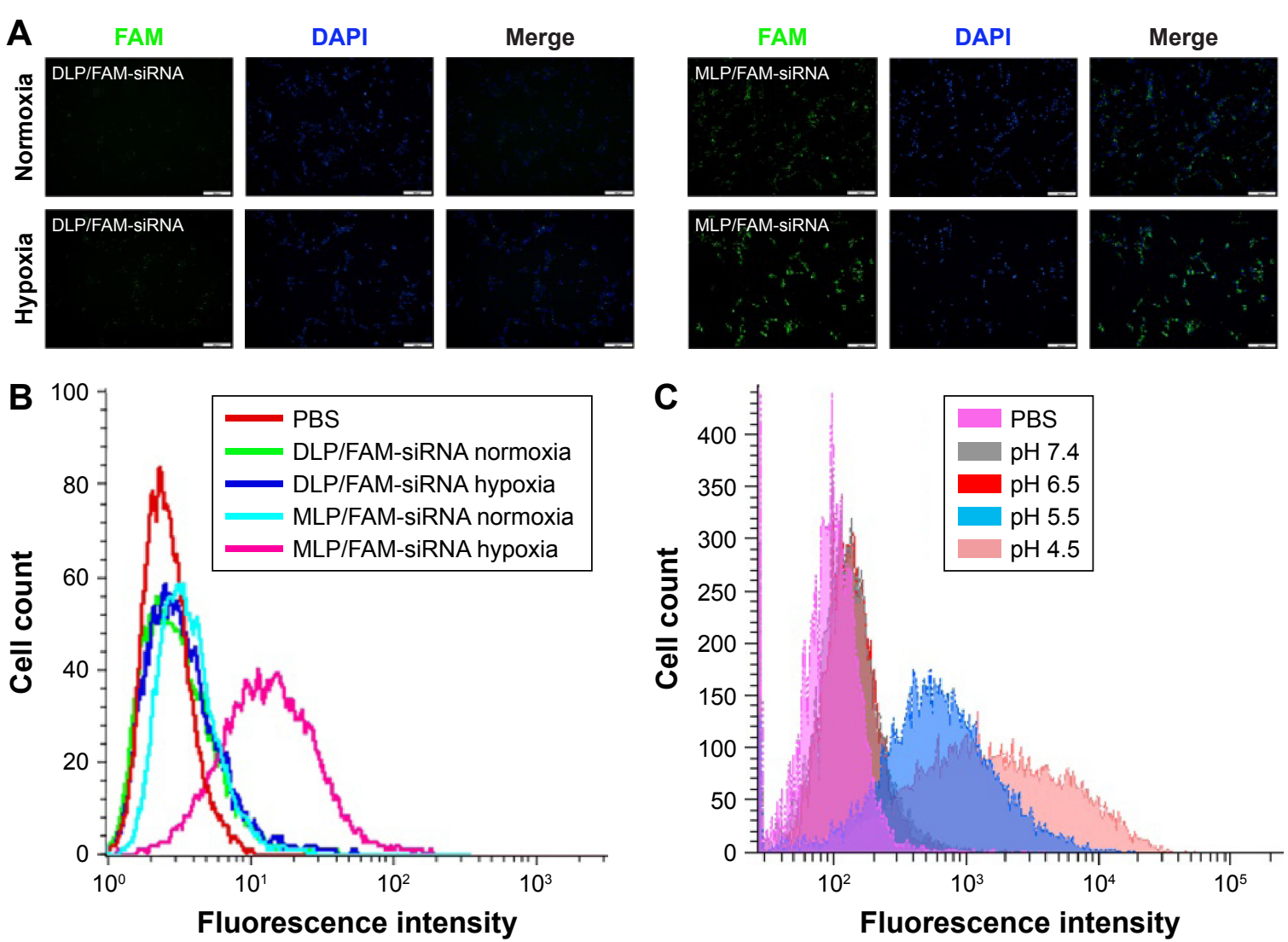

Figure 5 The fluorescence microscopy images and flow cytometry assay for intracellular uptake of MLP/siRNA by C6 cells.

Notes: (A) Fluorescence microscopy images of C6 cells with MLP/FAM-siRNA and DLP/FAM-siRNA incubation under hypoxia and normoxia for $4 \mathrm{~h}$ (scale bars $=200 \mu \mathrm{m}$ ). (B) Flow cytometric analysis of MLP/FAM-siRNA and DLP/FAM-siRNA uptake by C6 cells under hypoxia and normoxia for 4 h. (C) Cellular uptake of MLP/FAM-siRNA was analyzed by flow cytometry under $\mathrm{pH}$ values $7.4,6.5,5.5$, and 4.5 .

Abbreviations: DLP, Bis(palmitoyloxy)-3-(dimethylamino)propane liposomes; MLP, O'I,O'-(3-(dimethylamino)propane-I,2-diyl) I6-bis(2-(2-methyl-5-nitro-I H-imidazol-I-yl) ethyl) di(hexadecanedioate) liposomes; PBS, phosphate-buffered saline; siRNA, small interference RNA; DAPI, 4',6-diamidino-2-phenylindole.

These results coincided with the previously reported ones that cationic surface charge in most NPs correlates with higher cellular uptake in nonphagocytic cells. ${ }^{36}$ Altogether, our data suggest that the uptake of the MLP/siRNA is better after increasing the positive charge in lipoplexes as a result of conversion of nitroimidazoles to aminoimidazoles under hypoxic condition.

It has been reported that tertiary amines possess positive charge density in low $\mathrm{pH}$ value and tertiary-amine-functionalized NPs have enhanced cellular uptake in acidic extracellular microenvironment. ${ }^{15,40,41}$ Tertiary amine is the hydrophilic head group of MDH. Therefore, it is likely that MLP delivery of siPLK1 would increase uptake of siPLK1 by tumor cells. To elucidate the relationship between the cellular uptake of MLP/siPLK1 and $\mathrm{pH}$ value, C6 cells were incubated with MLP/FAM-siRNA for $4 \mathrm{~h}$. As shown in Figure 5C, the FAM-siRNA fluorescence intensities were found to be increased in $\mathrm{pH}$ values 5.5 and 4.5. The results coincided with the previous report that tertiary amine NPs increased cellular uptake in tumor. ${ }^{41}$

\section{Gene silencing and apoptosis-inducing capability}

We next assessed the gene-silencing efficiency of MLP/ siPLK1 in C6 cells. To knock down the expression of the PLK1 mRNA, MLP/siPLK1 needs to efficiently escape to cytoplasm. To verify this hypothesis, the endosome escape of the MLP/siRNA was studied using CLSM. To estimate the effect of hypoxia on the endosome escape of the MLP/ siRNA in glioma cells, FAM-siRNA was encapsulated into MLP and endosomes were stained with LysoTraker Red. Cellular endosome escape was monitored after incubation with MLP/FAM-siRNA for 2 and $4 \mathrm{~h}$ under normoxic and hypoxic conditions. As shown in Figure 6, at 2 h, there was little difference between normoxic and hypoxic conditions. However, at $4 \mathrm{~h}$, significant endosome escape of MLP/FAM-siRNA was seen under hypoxic conditions (green FAM-siRNA deviates from red endosome), while endosome escape was not obvious under normoxic conditions. These findings suggest that endosome escape of the MLP/siRNA is more efficient after the increase of positive charge of lipoplexes because of the 


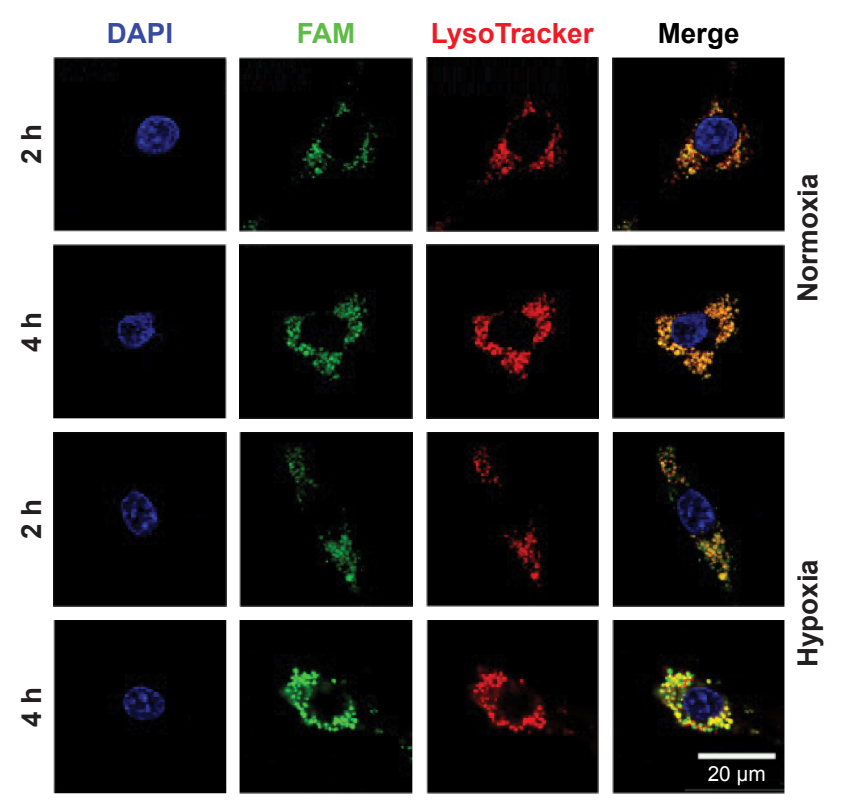

Figure 6 Confocal laser scan microscopy images of C6 cells with MLP/FAM-siRNA incubation under hypoxia and normoxia for 2 and $4 \mathrm{~h}$.

Notes: The nucleus was stained by Hoechst 33342, endosome was stained by LysoTraker Red, and FAM-siRNA was stained green (scale bar $=20 \mu \mathrm{m}$ ).

Abbreviations: siRNA, small interference RNA; DAPI, 4',6-diamidino-2-phenylindole.

MIs of MLP becoming protonated and positively charged under hypoxic condition.

The ability of MLP binding siPLK1 to silence gene expression was performed. PLK1, a serine/threonine-protein kinase, is an early trigger for G2/M transition during the cell cycle. PLK1 has been reported to play important roles in malignant glioma. ${ }^{34,42-44}$ RNAi-mediated PLK1 depletion or inhibition of PLK1 activity with siPLK1 induced G2/M arrest and apoptosis in glioma cells. Herein, the ability of downregulating therapeutic target mRNA level by siPLK1 delivered by MLP was assessed by RT-PCR. As shown in Figure 7A, MLP complexed with siPLK1 could significantly silence PLK1 gene expression in glioma cells under hypoxia, leading to $\sim 83.3 \%$ knockdown of PLK1 mRNA, whereas MLP/siPLK1 showed 47.4\% knockdown of PLK1 mRNA in glioma cells under normoxia. In contrast, negative control of DLP/siPLK1 showed similar knockdown of PLK1 mRNA $12.4 \%$ under hypoxia and $11.7 \%$ under normoxia, respectively. Meanwhile, the cells treated with PBS and free siPLK1 showed no knockdown efficiency. To follow transfection abilities with MLP/siPLK1, PLK1 protein expression levels were detected by Western blot analysis. MLP/siPLK1 exhibited significantly enhanced silencing of PLK1 protein expression under hypoxia (72.7\%) compared to that under normoxia (39.6\%; Figure $7 \mathrm{~B})$. These results coincided with the previous data of RT-PCR. The above results indicated that MLP/siPLK1 exerted the strongest gene downregulation ability under hypoxia, probably because of the high amount of MLP/siPLK1 uptaken by C6 cells under hypoxia.
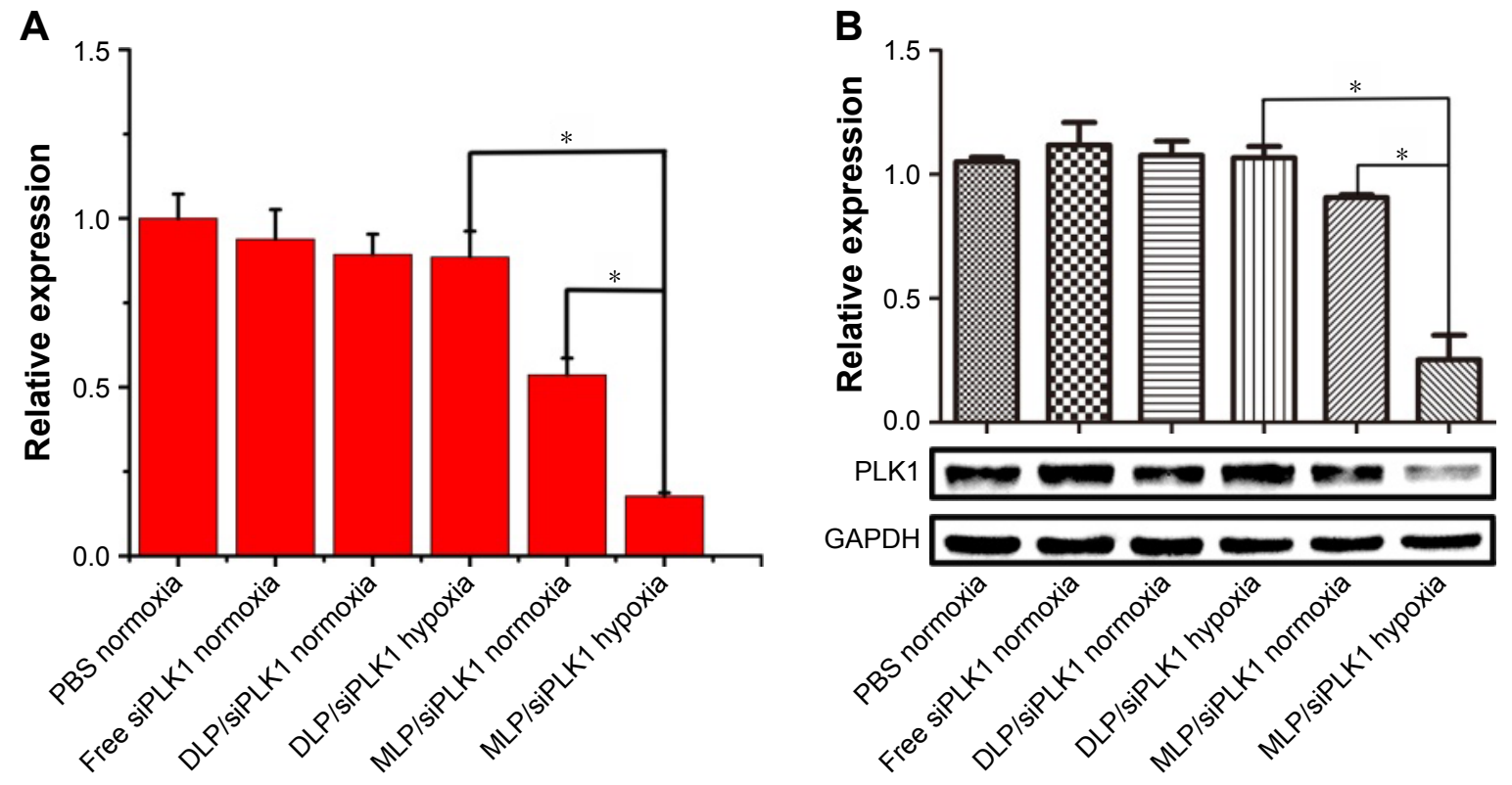

Figure 7 Real-time PCR analysis and Western blot analysis for MLP/siPLKI-mediated gene expression knockdown in vitro.

Notes: (A) Real-time PCR analysis of PLKI messenger RNA expression knockdown in C6 cells. (B) Western blot analysis of PLKI protein expression in C6 cells. The concentration of siPLKI was I $\mu \mathrm{g} \mathrm{mL} \mathrm{m}^{-1}$. Relative expression of PLKI protein knockdown of Western blot in C6 cells. Data are shown as mean \pm standard deviation ( $\mathrm{n}=3$ ), $* P<0.05$.

Abbreviations: DLP, Bis(palmitoyloxy)-3-(dimethylamino)propane liposomes; MLP, O',O'-(3-(dimethylamino)propane-I,2-diyl) I6-bis(2-(2-methyl-5-nitro-IH-imidazol-Iyl)ethyl) di(hexadecanedioate) liposomes; GAPDH, glyceraldehyde 3-phosphate dehydrogenase; PBS, phosphate-buffered saline; PCR, polymerase chain reaction; PLKI, polo-like kinase I; siPLKI, polo-like kinase I siRNA. 
Next, we estimated the apoptosis-inducing effect and proliferation inhibition of MLP loaded with siPLK1 using the Annexin V-FITC/PI apoptosis detection and MTT assay. As expected, the cells after treatment with MLP/siPLK1 under hypoxia showed the strongest apoptosis. The total apoptotic ratio, a sum of the early and late apoptotic ratios, was $16.9 \%$ in glioma under hypoxia (Figure $8 \mathrm{~A}$ ). However,
MLP/siPLK1 showed 9\% apoptotic ratio in glioma cell under normoxia. Negative control treatment with DLP/ siPLK1 showed a similar apoptotic ratio of $5.5 \%$ under hypoxia and $5.5 \%$ under normoxia, respectively. The cell treatments with PBS and free siPLK1 showed a ratio of $1.6 \%$ and $3.5 \%$, respectively. MTT test was employed to assess the proliferation inhibition of these liposomes in vitro, as
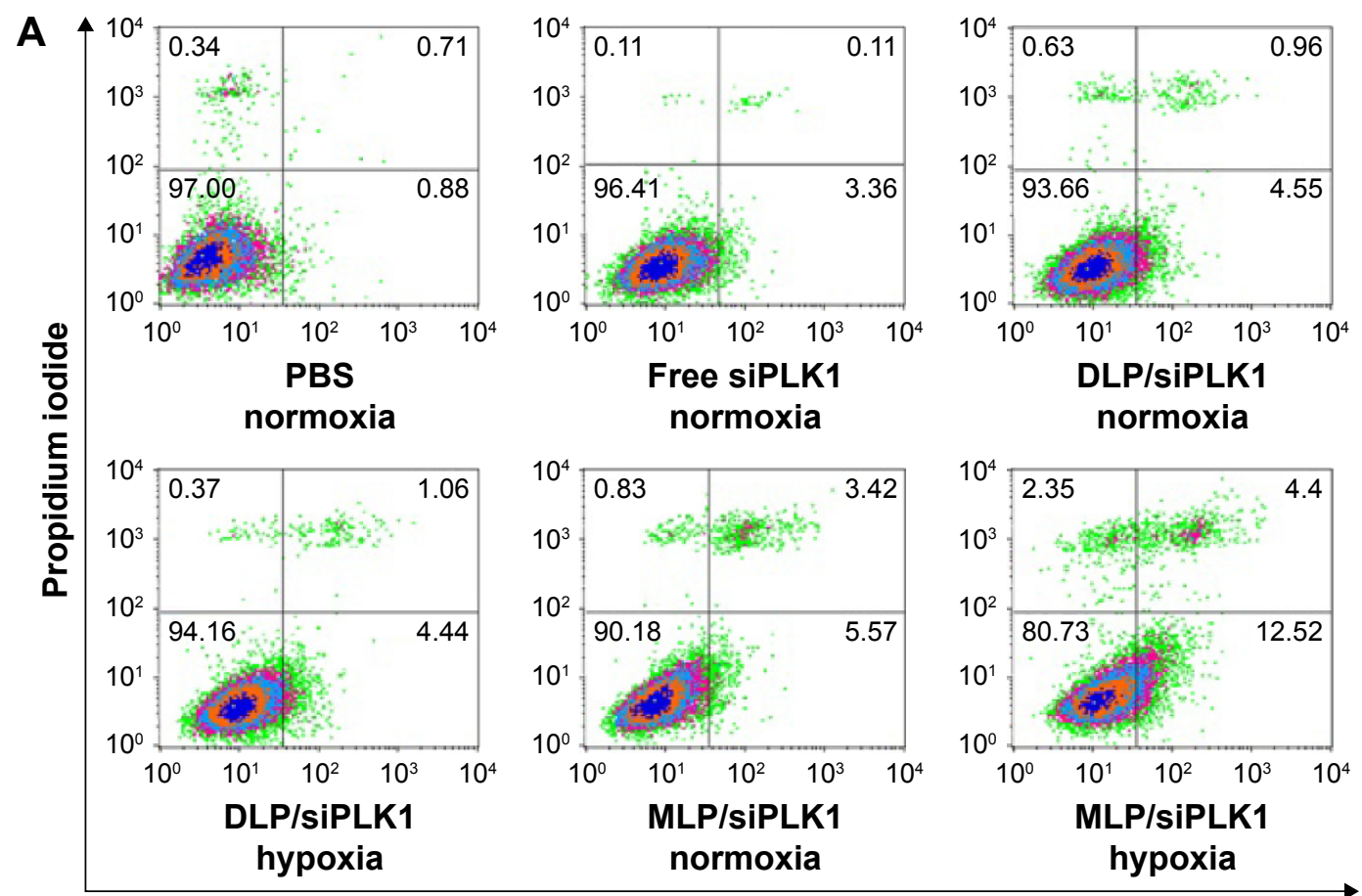

Annexin V-FITC

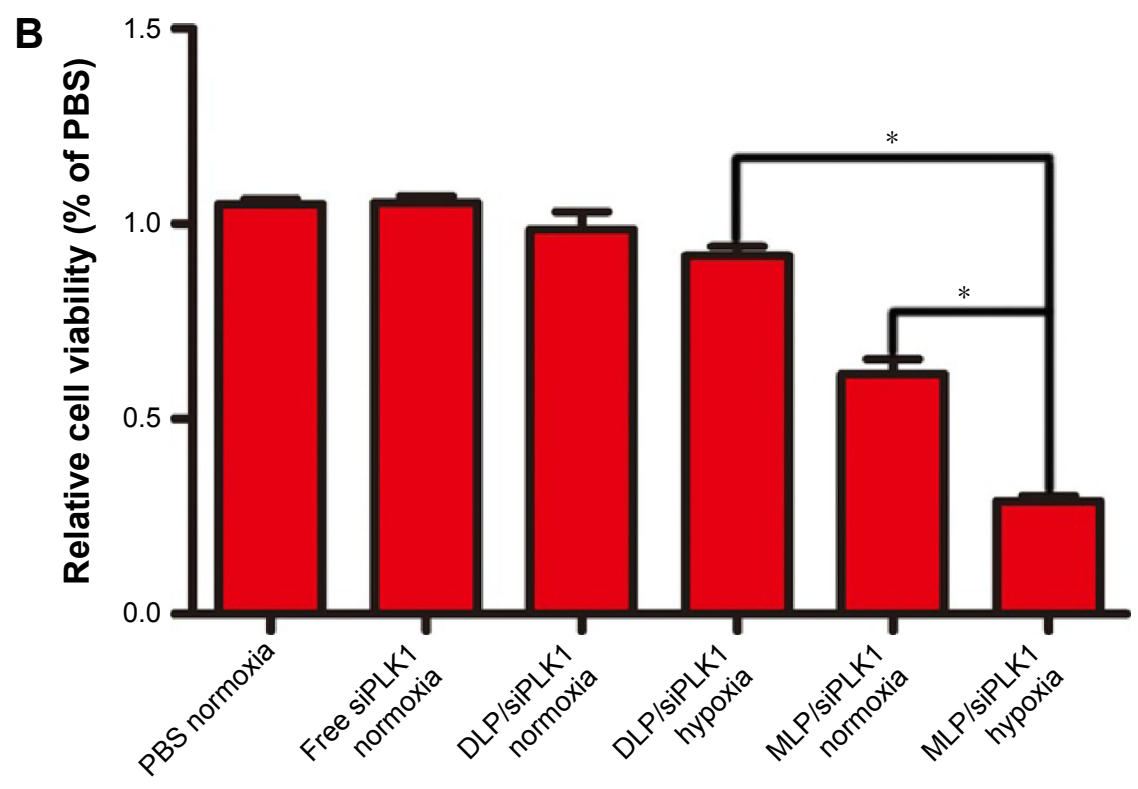

Figure 8 The assay of flow cytometry and MTT for C6 cell.

Notes: (A) Cell apoptosis of C6 cells induced by different treatments under normoxic and hypoxic conditions. (B) MTT assay of C6 cells under hypoxic conditions. Data are shown as mean \pm standard deviation $(n=3), * P<0.05$.

Abbreviations: DLP, Bis(palmitoyloxy)-3-(dimethylamino)propane liposomes; MLP, O',O'-(3-(dimethylamino)propane-I,2-diyl) I6-bis(2-(2-methyl-5-nitro-IH-imidazol- Iyl)ethyl) di(hexadecanedioate) liposomes; MTT, 3-(4,5-dimethylthiazol-2-yl)-2,5-diphenyltetrazolium bromide; PBS, phosphate-buffered saline; siPLKI, polo-like kinase I siRNA; FITC, fluorescein isothiocyanate. 
MTT incorporation assays showed that cell proliferation was significantly inhibited after MLP/siPLK1 treatment with glioma cells under hypoxia (72.2\%; Figure 8B), while it was $38.4 \%$ when glioma cells were treated with MLP/ siPLK1 under normoxia. However, there was no significant difference between the glioma cells treated with DLP/ siPLK1 under hypoxia and normoxia and both had little cell proliferation inhibition. These results confirmed that MLP/siPLK1 with high gene-silencing efficiency exhibited a superior apoptosis-inducing and proliferation inhibition capacity under hypoxic condition.

\section{Suppression of tumor growth in vivo}

In the experiment described above, we have demonstrated that MLP may have increased charges under hypoxic conditions in tumor. Thus, the detection of hypoxia in glioma played an essential role in optimizing the choice of antitumor regimens. To examine the hypoxic area in glioma, immunofluorescence assay was performed. Immunofluorescence imaging of C6 orthotopic implantation glioma displayed a substantial distribution of hypoxia (red regions in Figure 9), validating the feasibility for in vivo test of the antiglioma efficacy with MLP/ siPLK1. These results suggest that in the brain tumor, there is a large area of hypoxia. This result is consistent with the previous findings that there is hypoxia area in glioma. ${ }^{45-47}$

To reveal the potential of MLP as in vivo siRNA delivery system, we treated the C6-GFP-luci tumor-bearing ICR mice with MLP/Cy5-siRNA. It was expected that MLP/Cy5-siRNA could cross the blood-brain barrier (BBB) and enter into the tumor tissues by passive mechanisms because of the small size of MLP/siRNA. For this purpose, the brain tumor models were developed in ICR mice using stereotactic intracranial injection of $1 \times 10^{5}$ C6-GFP-luci cells into the primary somatosensory cortex. Seven days postimplantation, the bioluminescence signals were analyzed by in vivo bioluminescence imaging. As shown in Figure 10A, the in vivo imaging confirmed the existence of brain glioma and demonstrated that mice injected with DLP/Cy5-siRNA and MLP/Cy5siRNA had the similar volumes of glioma. And then, DLP/ Cy5-siRNA, MLP/Cy5-siRNA, and free Cy5-siRNA were administered intravenously to the ICR mice, which were then examined after $4 \mathrm{~h}$ using an in vivo imaging system and fluorescence microscopy, respectively. As shown in Figure $10 \mathrm{~B}$ and $\mathrm{C}$, the strongest $\mathrm{Cy} 5$ fluorescence was observed in glioma in case of DLP/Cy5-siRNA and MLP/ Cy5-siRNA, indicating that DLP/Cy5-siRNA and MLP/Cy5siRNA were accumulated in the brain tumor by enhanced permeability retention (EPR) effect. Meanwhile, much less Cy5 fluorescence was observed after injection of free Cy5-siRNA, because free Cy5-siRNA injected into the blood showed an extremely rapid degradation and clearance in the body. Moreover, compared with other groups, the strongest Cy5 fluorescence was observed after injecting with MLP/Cy5siRNA. Marked MLP/Cy5-siRNA accumulation in the tumor may be due to the EPR effect and increased positive surface charges of MLP that help its cellular uptake in glioma acidic extracellular and hypoxic microenvironment in the tumor. The distribution of DLP/Cy5-siRNA, MLP/Cy5-siRNA, and free $\mathrm{Cy} 5$ was also confirmed by frozen tumor tissue section observed by fluorescence microscope (Figure 10D). Brain tumor tissues were identified as hypercellularity areas as evident from DAPI-stained cell nuclei shown in blue and the C6-GFP-luci expression in green (Figure 10D). The C6-GFP-luci-bearing mice injected with MLP/Cy5-siRNA had more Cy5 fluorescence in brain tumor than those injected with free Cy5-siRNA and DLP/Cy5-siRNA, indicating that $\mathrm{MLP} / \mathrm{siRNA}$ can deliver siRNA to brain tumor. Together, these findings demonstrate that MLP/Cy5-siRNA is able to successfully deliver siRNA to penetrate the BBB and target tumor in vivo.
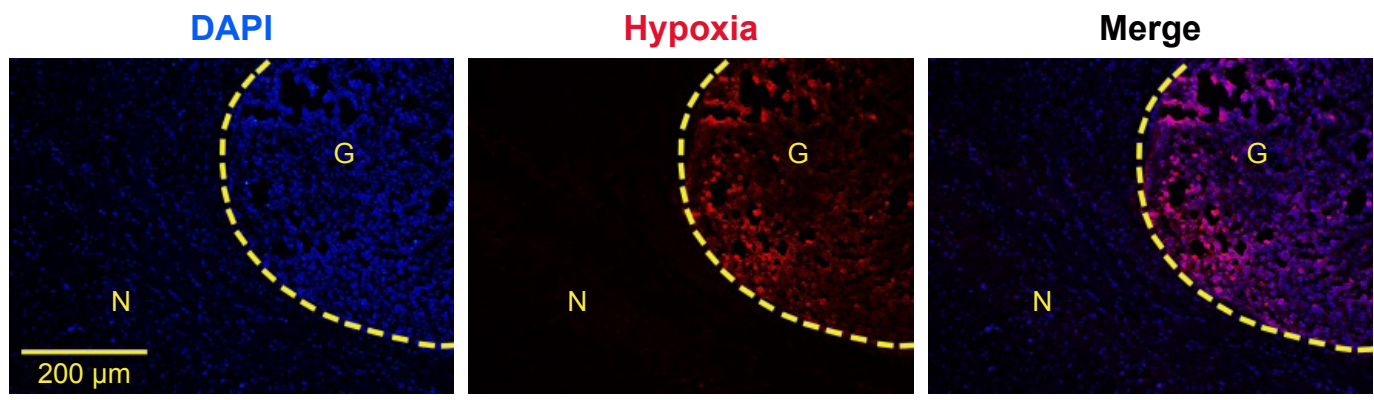

Figure 9 Immunofluorescence assay after MAbI (Hypoxyprobe ${ }^{T M}-I$ Kit), which can bind to protein, peptide, and amino acid adducts of 2-nitroimidazole in hypoxic cells, was added to tumor tissue sections: red regions are hypoxic tissues.

Note: Scale bar $=200 \mu \mathrm{m}$.

Abbreviations: DAPI, 4',6-diamidino-2-phenylindole; N, normal brain tissue; G, glioma tissue. 

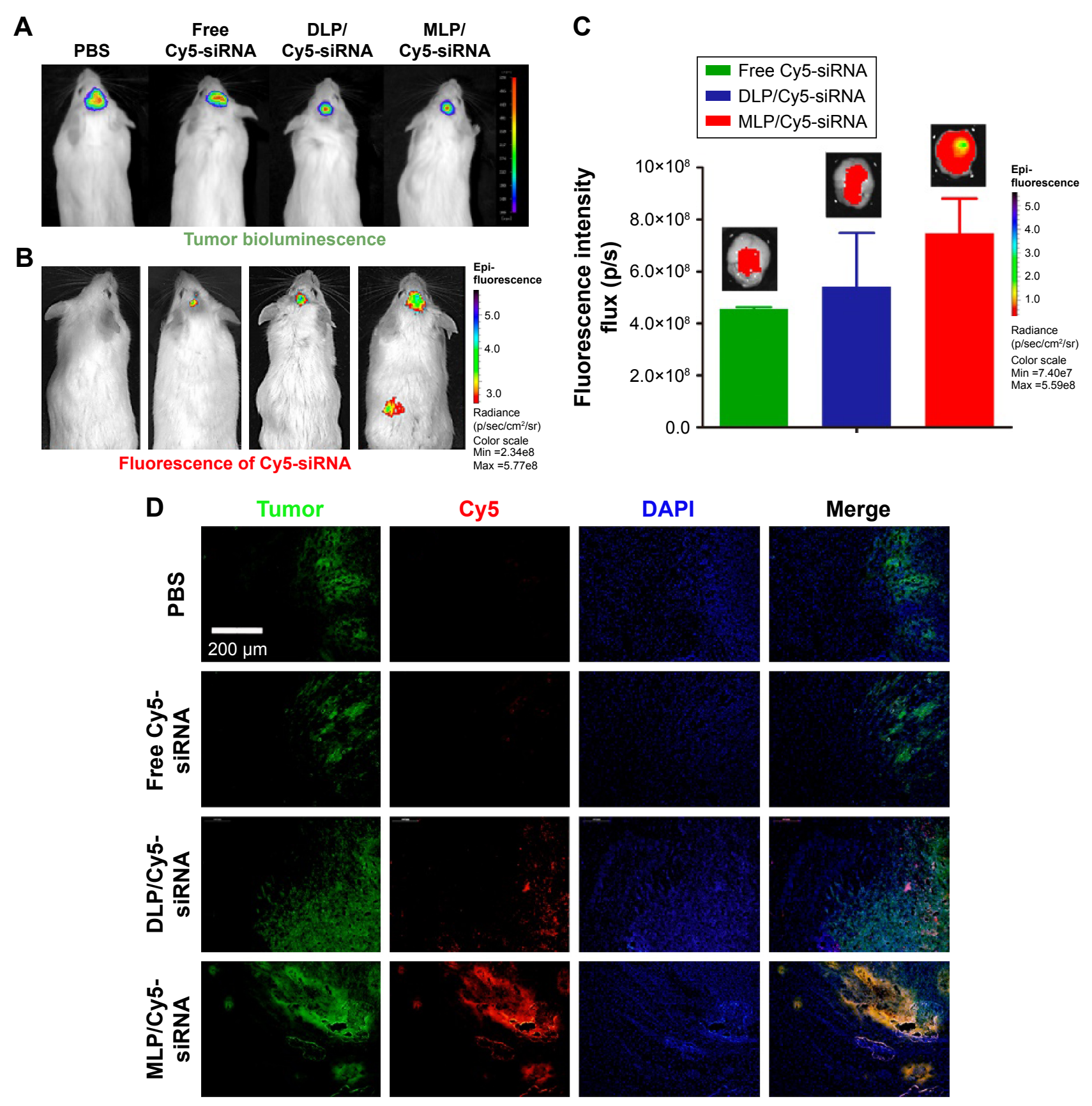

Figure 10 Living imaging of C6-GFP-luci tumor-bearing mice $4 \mathrm{~h}$ after DLP/Cy5-siRNA, MLP/Cy5-siRNA, and free Cy5-siRNA were intravenously injected.

Notes: (A) Bioluminescence of luciferase-expressing tumor cells 10 min following intraperitoneal injection of luciferin solution. (B) In vivo imaging fluorescence signal of Cy5-labeled siRNA. (C) Ex vivo imaging brain fluorescence signal of Cy5-labeled siRNA. (D) Fluorescent microscope images show the distribution of Cy5-siRNAs in glioma following intravenous injection of free Cy5-siRNAs and MLP/Cy5-siRNAs. Cy5-siRNAs (red), tumor (green), and cell nuclei are stained with 4',6-diamidino-2-phenylindole (blue). Scale bar $=200 \mu \mathrm{m}$.

Abbreviations: DLP, Bis(palmitoyloxy)-3-(dimethylamino)propane liposomes; MLP, O'I,O'-(3-(dimethylamino)propane-I,2-diyl) I6-bis(2-(2-methyl-5-nitro-IH-imidazol-Iyl)ethyl) di(hexadecanedioate) liposomes; PBS, phosphate-buffered saline; siRNA, small interference RNA.

Next, we examined the antitumor growth effect of MLP/ siPLK1 after its accumulation in the tumor site. C6 cells genetically modified to express the luciferase enzyme were inoculated intracranially for 10 days prior to local administration of free siPLK1, MLP/nonsense siRNA, DLP/siPLK1, and MLP/siPLK1. The intensity of bioluminescence was used to monitor the tumor growth. Tumors in the control group and mice treated with free siPLK1 grew rapidly (Figure 11A and B). By day 27, the tumors injected with PBS and free siPLK1 group, as reflected by bioluminescence measurements, were 48-fold and 47-fold higher than at day 10 , respectively. The tumor growth rate in mice that were treated with DLP/siPLK1 was slower than that of the PBS treatment group, with tumor load equal to $64.6 \%$ of the PBS 
A

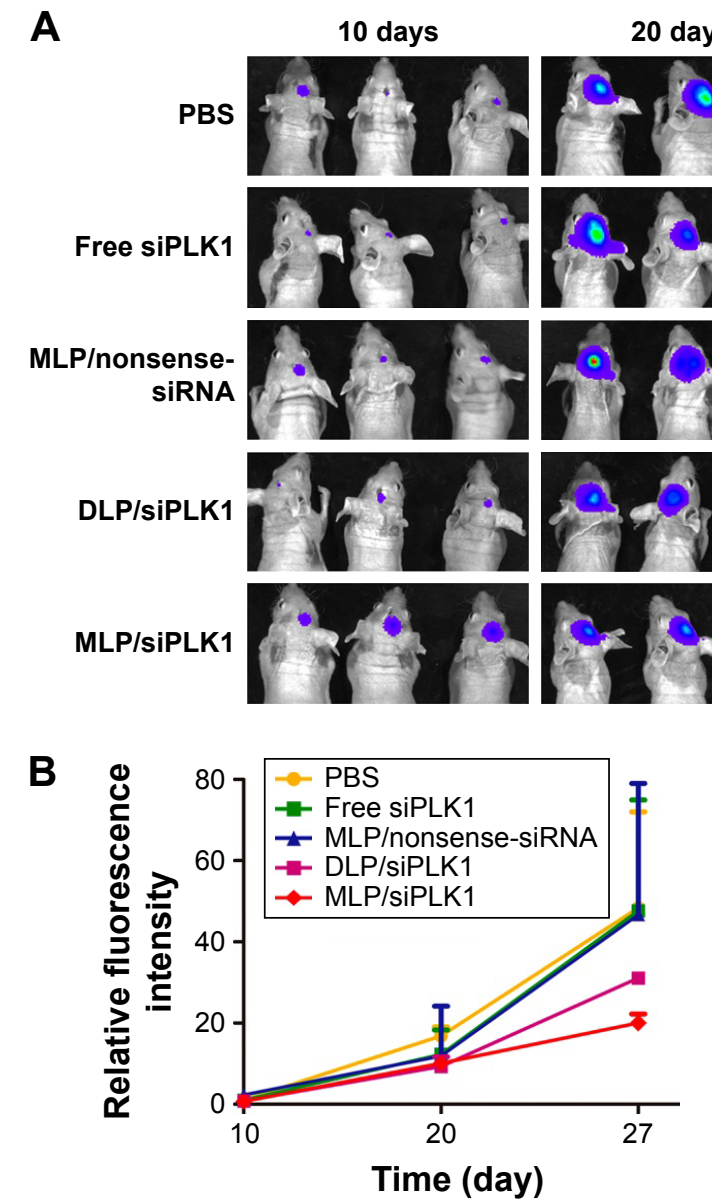

20 days

27 days
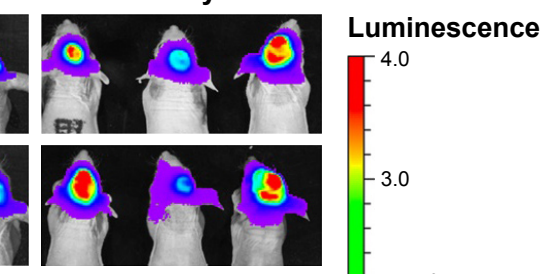

$-3.0$

$\stackrel{\infty}{\frac{\rho}{x}}$
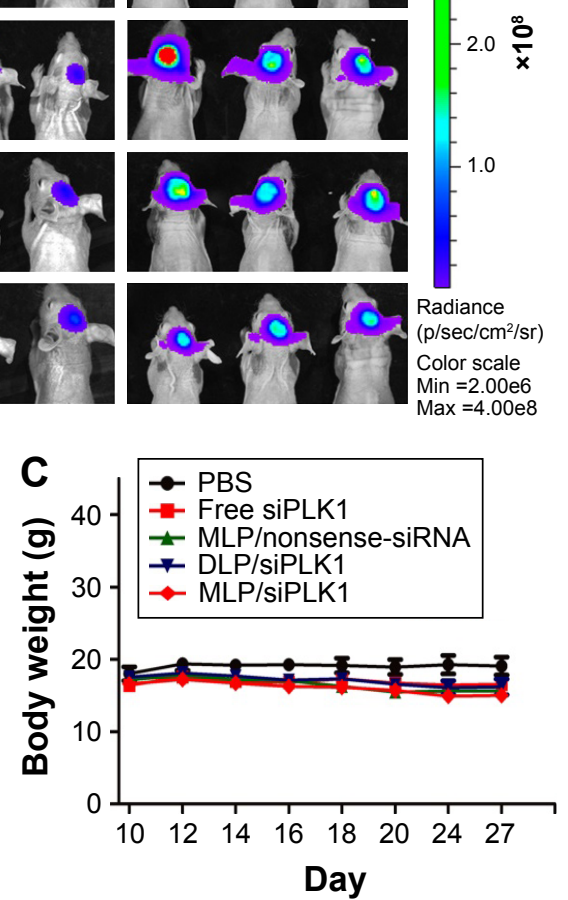

Figure II Living imaging and body weight of C6-GFP-luci tumor-bearing mice.

Notes: (A) Living imaging of C6-GFP-luci tumor-bearing mice of different groups after treating with liposome/siPLKI at a dose of I mg kg ${ }^{-1}$. $\mathrm{n}=5$. (B) Relative fluorescence intensity of C6-GFP-luci tumor-bearing mice. (C) Body weight of C6-GFP-luci tumor-bearing mice.

Abbreviations: DLP, Bis(palmitoyloxy)-3-(dimethylamino)propane liposomes; MLP, O'I,O'-(3-(dimethylamino)propane-I,2-diyl) I6-bis(2-(2-methyl-5-nitro-I H-imidazol-Iyl)ethyl) di(hexadecanedioate) liposomes; GFP, green fluorescent protein; siPLKI, polo-like kinase I siRNA; PBS, phosphate-buffered saline; siRNA, small interference RNA.

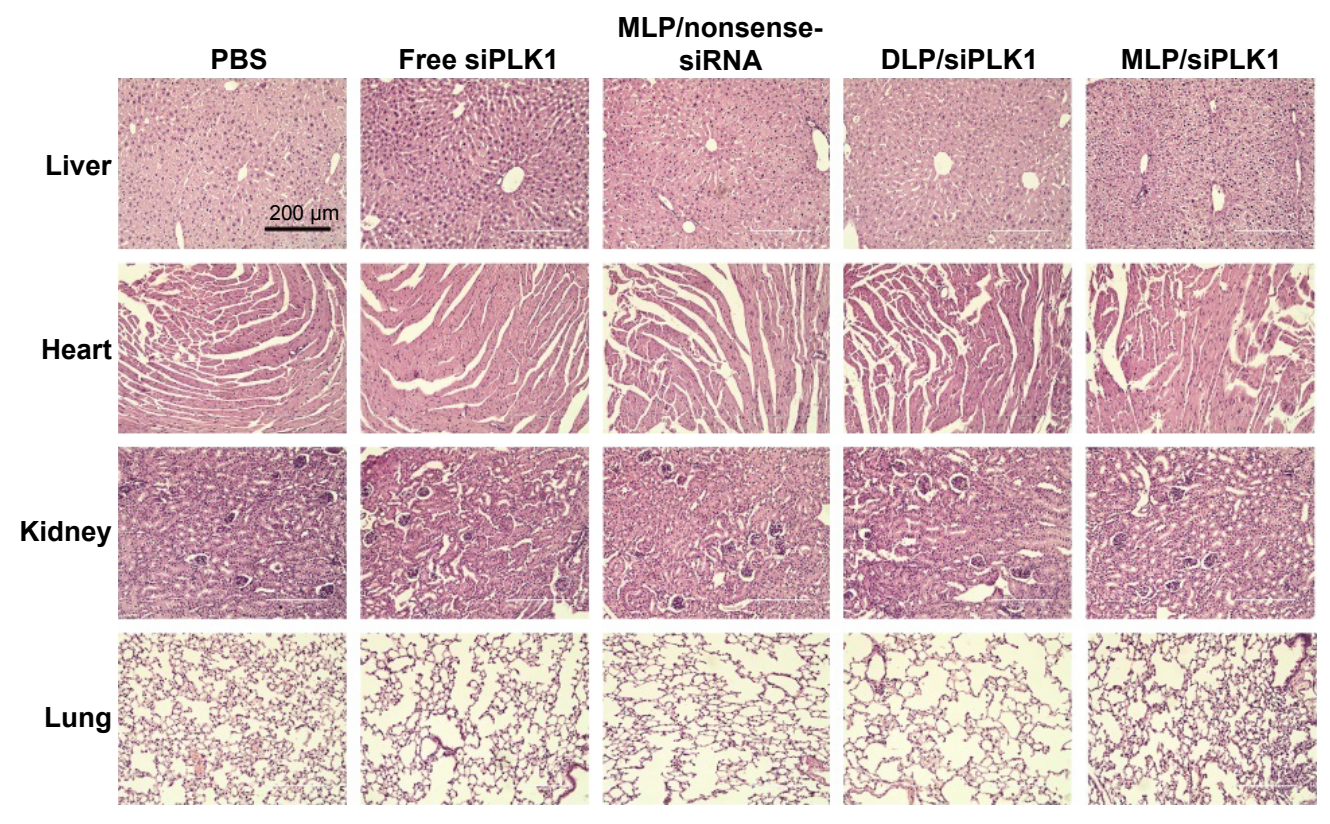

Figure 12 Image of main organs collected from C6-GFP-luci tumor-bearing nude mice after the mice were treated by liposome/siPLKI at the last time. Note: Organs were stained with hematoxylin and eosin (scale bar $=200 \mu \mathrm{m}$ ).

Abbreviations: DLP, Bis(palmitoyloxy)-3-(dimethylamino)propane liposomes; MLP, O'I,O'-(3-(dimethylamino)propane-I,2-diyl) I6-bis(2-(2-methyl-5-nitro-IH-imidazol-Iyl)ethyl) di(hexadecanedioate) liposomes; siPLKI, polo-like kinase I siRNA; PBS, phosphate-buffered saline; siRNA, small interference RNA. 
treatment group by day 27 . However, the tumor treated with $\mathrm{MLP} / \mathrm{siPLK} 1$ group was only $41.1 \%$ of PBS treatment group and statistically lower that of any other group at day 27. The above results suggest that MLP/siPLK1 can effectively inhibit the growth of glioma.

To evaluate the toxicities of different formulations, weights of nude mice and sections of main organs (including heart, liver, lung, and kidney, were stained with H\&E) of different groups were described. As shown in Figure 11C, there was no significant difference of weight between different groups. The H\&E staining images of major organs are shown in Figure 12, and no noticeable tissue damage or obvious changes in morphology were observed in all of the organs from the DLP/siPLK1 and MLP/siPLK1 groups, compared with that of the PBS group. The in vivo results suggested that the MLP had fine biocompatibility, and had potential biological applications with little side effect.

\section{Conclusion}

In summary, we have developed a hypoxia-responsive ionizable liposome (MLP) to deliver antitumor siRNA for glioma therapy. Due to the properties of tertiary amines and nitroimidazoles, the MLP/siRNA could increase the surface positive charge under low extracellular $\mathrm{pH}$ and hypoxic tumor microenvironment. In vivo imaging and histological and microscopic examinations of brain tissue confirmed that the MLP effectively delivered siRNA into glioma. Furthermore, MLP/siRNA was found to significantly inhibit the growth of glioma as assessed by in vivo bioluminescence imaging. These findings suggest that MLP is a promising candidate as siRNA delivery system for the treatment of brain glioma.

\section{Acknowledgments}

This work was financially supported by National Natural Science Foundation of China (grants no 81272777, 81502153, 81472345), Natural Science Foundation of Jiangsu Province (grant no BK20150221), China Postdoctoral Science Foundation (grant no 2016M591926), and Key Research \& Development Plan of Jiangsu Province (grant no BE2016646).

\section{Disclosure}

The authors report no conflicts of interest in this work.

\section{References}

1. Bumcrot D, Manoharan M, Koteliansky V, Sah DWY. RNAi therapeutics: a potential new class of pharmaceutical drugs. Nat Chem Biol. 2006; 2(12):711-719.

2. Maraganore J. RNAi Therapeutics: state of the State. Nucleic Acid Ther. 2012;22:A2-A2.

3. Davidson BL, McCray PB Jr. Current prospects for RNA interferencebased therapies. Nature Rev Genet. 2011;12(5):329-340.
4. Davis ME, Zuckerman JE, Choi CH, et al. Evidence of RNAi in humans from systemically administered siRNA via targeted nanoparticles. Nature. 2010;464(7291):1067-1070.

5. Vaishnaw AK, Gollob J, Gamba-Vitalo C, et al. A status report on RNAi therapeutics. Silence. 2010;1(1):14.

6. Whitehead KA, Langer R, Anderson DG. Knocking down barriers: advances in siRNA delivery. Nat Rev Drug Discov. 2009;8(2): 129-138.

7. Yin LC, Song ZY, Kim KH, Zheng N, Gabrielson NP, Cheng JJ. Nonviral gene delivery via membrane-penetrating, mannose-targeting supramolecular self-assembled nanocomplexes. Adv Mater. 2013;25(22): 3063-3070.

8. Truong NP, Gu WY, Prasadam I, et al. An influenza virus-inspired polymer system for the timed release of siRNA. Nat Commun. 2013;4:54-56.

9. Kim JS, Oh MH, Park JY, Park TG, Nam YS. Protein-resistant, reductively dissociable polyplexes for in vivo systemic delivery and tumor-targeting of siRNA. Biomaterials. 2013;34(9):2370-2379.

10. Prakash TP, Lima WF, Murray HM, et al. Lipid nanoparticles improve activity of single-stranded siRNA and gapmer antisense oligonucleotides in animals. ACS Chem Biol. 2013;8(7):1402-1406.

11. Huang L, Liu Y. In vivo delivery of RNAi with lipid-based nanoparticles. Annu Rev Biomed Eng. 2011;13:507-530.

12. Ballarin-Gonzalez B, Howard KA. Polycation-based nanoparticle delivery of RNAi therapeutics: adverse effects and solutions. Adv Drug Deliv Rev. 2012;64(15):1717-1729.

13. Soenen SJ, Nuytten N, De Smedt SC, De Cuyper M. Investigating the effects of cationic lipid-mediated toxicity and how to optimize liposomal systems for transfection purposes. Drug Discov Today. 2010;15: 1081-1082.

14. Sato Y, Hatakeyama H, Sakurai Y, Hyodo M, Akita H, Harashima H. A pH-sensitive cationic lipid facilitates the delivery of liposomal siRNA and gene silencing activity in vitro and in vivo. J Control Release. 2012; 163(3):267-276.

15. Semple SC, Akinc A, Chen JX, et al. Rational design of cationic lipids for siRNA delivery. Nat Biotechnol. 2010;28(2):172-176.

16. Love KT, Mahon KP, Levins CG, et al. Lipid-like materials for low-dose, in vivo gene silencing. P Natl Acad Sci US A. 2010;107(5):1864-1869.

17. Maiti PK, Cagin T, Lin ST, Goddard WA. Effect of solvent and $\mathrm{pH}$ on the structure of PAMAM dendrimers. Macromolecules. 2005; 38(3):979-991.

18. Liu Y, Huang L. Designer lipids advance systemic siRNA delivery. Mol Ther. 2010;18(4):669-670.

19. Bachelder EM, Beaudette TT, Broaders KE, Dashe J, Frechet JM. Acetalderivatized dextran: an acid-responsive biodegradable material for therapeutic applications. J Am Chem Soc. 2008;130(32):10494-10495.

20. Griset AP, Walpole J, Liu R, Gaffey A, Colson YL, Grinstaff MW. Expansile nanoparticles: synthesis, characterization, and in vivo efficaCy of an acid-responsive polymeric drug delivery system. J Am Chem Soc. 2009;131(7):2469-2471.

21. Lee ES, Gao Z, Kim D, Park K, Kwon IC, Bae YH. Super pH-sensitive multifunctional polymeric micelle for tumor $\mathrm{pH}(\mathrm{e})$ specific TAT exposure and multidrug resistance. J Control Release. 2008;129(3): 228-236.

22. Lee ES, Na K, Bae YH. Super $\mathrm{pH}$-sensitive multifunctional polymeric micelle. Nano Lett. 2005;5(2):325-329.

23. Mukherjee K, Sen J, Chaudhuri A. Common co-lipids, in synergy, impart high gene transfer properties to transfection-incompetent cationic lipids. FEBS Lett. 2005;579(5):1291-1300.

24. Felgner JH, Kumar R, Sridhar CN, et al. Enhanced gene delivery and mechanism studies with a novel series of cationic lipid formulations. J Biol Chem. 1994;269(4):2550-2561.

25. Hafez IM, Maurer N, Cullis PR. On the mechanism whereby cationic lipids promote intracellular delivery of polynucleic acids. Gene Ther. 2001;8(15):1188-1196.

26. Moyer MW. Targeting hypoxia brings breath of fresh air to cancer therapy. Nat Med. 2012;18(5):636-637.

27. Wilson WR, Hay MP. Targeting hypoxia in cancer therapy. Nat Rev Cancer. 2011;11(6):393-410. 
28. Harris AL. Hypoxia - a key regulatory factor in tumour growth. Nat Rev Cancer. 2002;2(1):38-47.

29. Brown JM, Wilson WR. Exploiting tumour hypoxia in cancer treatment. Nat Rev Cancer. 2004;4(6):437-447.

30. Takasawa M, Moustafa RR, Baron JC. Applications of nitroimidazole in vivo hypoxia imaging in ischemic. Stroke. 2008;39(5):1629-1637.

31. Wang Y, Zhou K, Huang G, et al. A nanoparticle-based strategy for the imaging of a broad range of tumours by nonlinear amplification of microenvironment signals. Nat Mater. 2014;13(2):204-212.

32. Thambi T, Deepagan VG, Yoon HY, et al. Hypoxia-responsive polymeric nanoparticles for tumor-targeted drug delivery. Biomaterials. 2014; 35(5):1735-1743.

33. Overgaard J. Hypoxic radiosensitization: adored and ignored. J Clin Oncol. 2007;25(26):4066-4074.

34. Cohen ZR, Ramishetti S, Peshes-Yaloz N, et al. Localized RNAi therapeutics of chemoresistant grade IV glioma using hyaluronan-grafted lipid-based nanoparticles. ACS Nano. 2015;9(2):1581-1591.

35. Liu H, Qiao C, Yang J, Weng J, Zhang X. Self-assembling doxorubicinprodrug nanoparticles as siRNA drug delivery system for cancer treatment: in vitro and in vivo. J Mater Chem. 2014;2(35):5910-5924.

36. Baumann RP, Penketh PG, Seow HA, Shyam K, Sartorelli AC. Generation of oxygen deficiency in cell culture using a two-enzyme system to evaluate agents targeting hypoxic tumor cells. Radiat Res. 2008; 170(5):651-660.

37. Maurer N, Wong KF, Stark H, et al. Spontaneous entrapment of polynucleotides upon electrostatic interaction with ethanol-destabilized cationic liposomes. Biophys J. 2001;80(5):2310-2326.

38. Yu B, Zhang Y, Zheng W, Fan C, Chen T. Positive surface charge enhances selective cellular uptake and anticancer efficacy of selenium nanoparticles. Inorganic Chemistry. 2012;51(16):8956-8963.
39. Frohlich E. The role of surface charge in cellular uptake and Cytotoxicity of medical nanoparticles. Int J Nanomedicine. 2012;7:5577-5591.

40. Jin X, Kataoka K, Yatabe T, Yamaguchi K, Mizuno N. Supported Gold Nanoparticles for Efficient alpha-Oxygenation of Secondary and Tertiary Amines into Amides. Angew Chem Int Ed Engl. 2016;55(25): $7212-7217$.

41. Lo CW, Chang Y, Lee JL, Tsai WB, Chen WS. Tertiary-amine functionalized polyplexes enhanced cellular uptake and prolonged gene expression. PloS One. 2014;9(5):e97627.

42. Cheng MW, Wang BC, Weng ZQ, Zhu XW. Clinicopathological significance of Polo-like kinase 1 (PLK1) expression in human malignant glioma. Acta Histochem. 2012;114(5):503-509.

43. Yao YD, Sun TM, Huang SY, et al. Targeted delivery of PLK1-siRNA by $\mathrm{ScFv}$ suppresses Her2+ breast cancer growth and metastasis. Sci Transl Med. 2012;4(130):3042-3046.

44. Signore M, Pelacchi F, di Martino S, et al. Combined PDK1 and CHK1 inhibition is required to kill glioblastoma stem-like cells in vitro and in vivo. Cell Death \& Dis. 2014;5:288-295.

45. Evans SM, Judy KD, Dunphy I, et al. Hypoxia is important in the biology and aggression of human glial brain tumors. Clin Cancer Res. 2004;10(24):8177-8184.

46. Moulder JE, Rockwell S. Tumor hypoxia: its impact on cancer therapy. Cancer Metastasis Rev. 1987;5(4):313-341.

47. Vaupel P, Mayer A. Hypoxia and anemia: effects on tumor biology and treatment resistance. Transfus Clin Biol. 2005;12(1):5-10. 


\section{Supplementary materials}

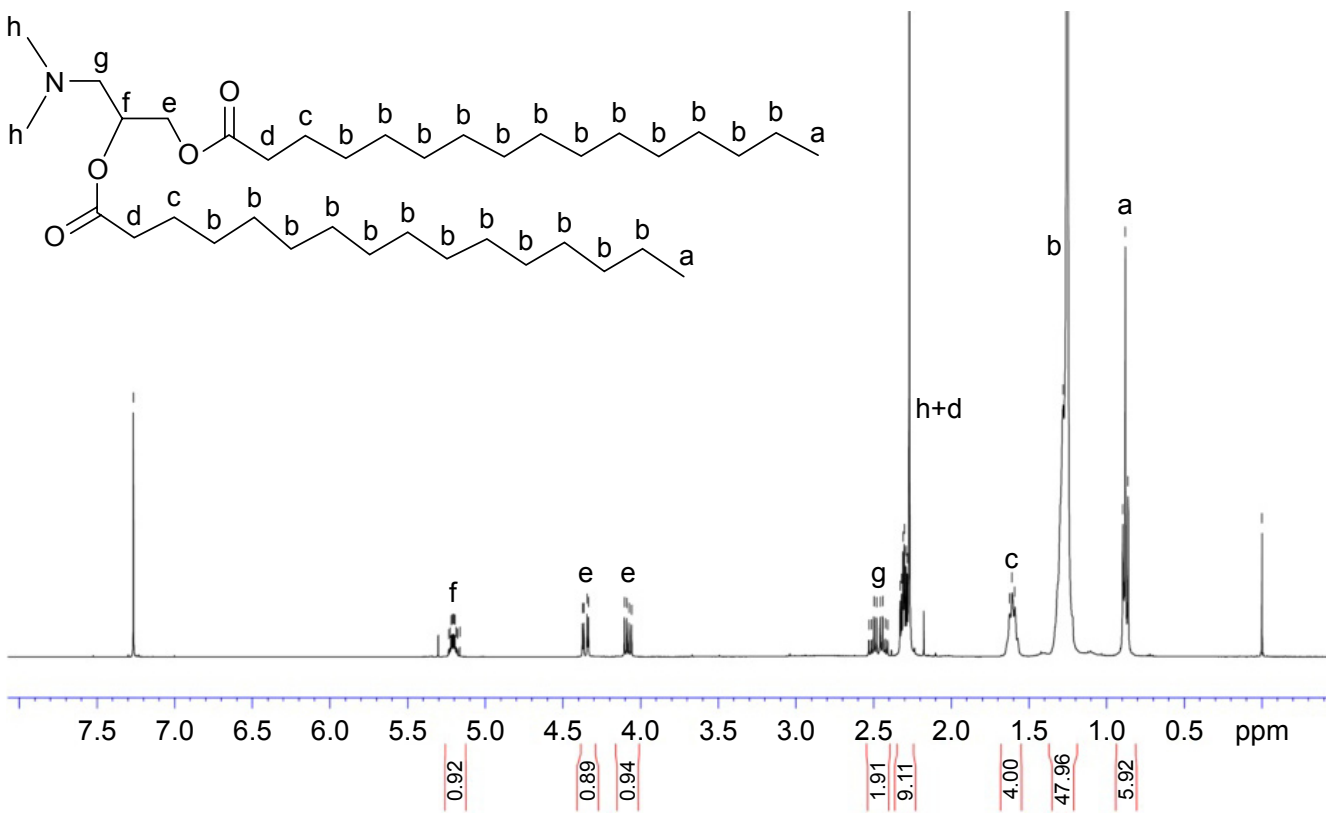

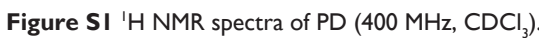

Abbreviation: NMR, nuclear magnetic resonance.

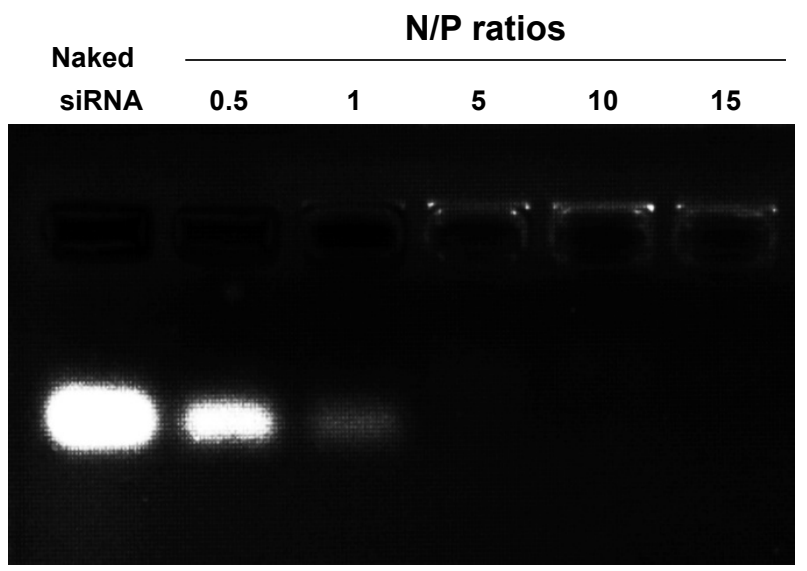

Figure S2 Gel retardation assay of DLP complexation efficiency of siRNA at various $\mathrm{N} / \mathrm{P}$ ratios.

Abbreviations: siRNA, small interference RNA; N/P, nitrogen/phosphate; DLP, Bis(palmitoyloxy)-3-(dimethylamino)propane liposomes.

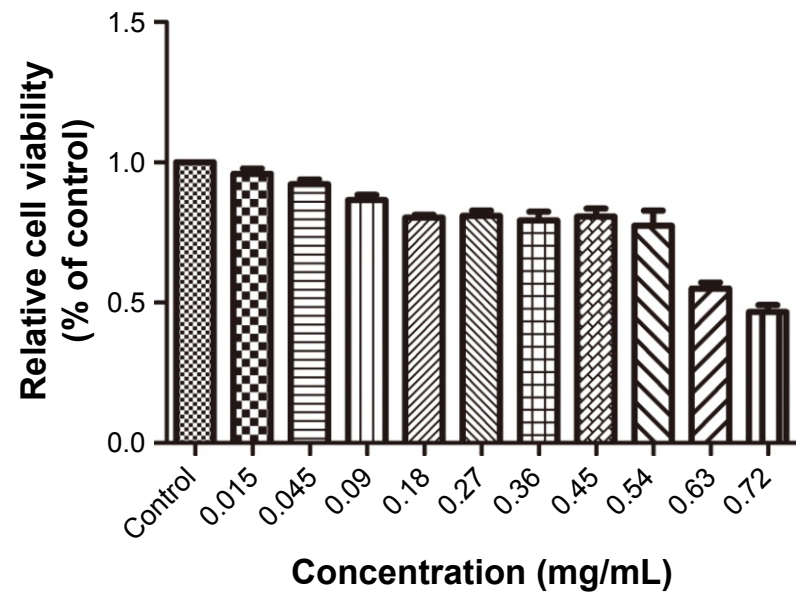

Figure S3 3-(4,5-Dimethylthiazol-2-yl)-2,5-diphenyltetrazolium bromide assay of C6 cells with different concentrations of MLP.

Note: Data are shown as mean \pm standard deviation $(n=5)$.

Abbreviation: MLP, $\mathrm{O}^{\prime \prime}, \mathrm{O}^{\prime}$-(3-(dimethylamino)propane-1,2-diyl) 16-bis(2-(2methyl-5-nitro- $\mid \mathrm{H}$-imidazol-I-yl)ethyl) di(hexadecanedioate) liposomes.
International Journal of Nanomedicine

\section{Publish your work in this journal}

The International Journal of Nanomedicine is an international, peerreviewed journal focusing on the application of nanotechnology in diagnostics, therapeutics, and drug delivery systems throughou the biomedical field. This journal is indexed on PubMed Central, MedLine, CAS, SciSearch ${ }^{\circledR}$, Current Contents ${ }^{\circledR} /$ Clinical Medicine,

\section{Dovepress}

Journal Citation Reports/Science Edition, EMBase, Scopus and the Elsevier Bibliographic databases. The manuscript management system is completely online and includes a very quick and fair peer-review system, which is all easy to use. Visit http://www.dovepress.com/ testimonials.php to read real quotes from published authors. 